\title{
THE SURGICAL AND PATHOLOGICAL ANATOMY OF THE MITRAL VALVE
}

\author{
BY \\ R. C. BROCK \\ From the Thoracic Unit, Guy's Hospital \\ Received July 14, 1952
}

The great practical importance that mitral valve disease has now assumed in surgery demands a consideration of the anatomy and function of the normal valve and the pathological anatomy of the diseased valve. Observation on many normal and diseased specimens and direct study of the valve at some 150 operations has made it clear to me that much that is now taught is quite unacceptable. The revision and extension of existing knowledge has often been seen in the development of the surgery of all parts of the body; relatively recently we have seen the great expansion of pulmonary surgery and the corresponding intensive study of pulmonary anatomy and pathology.

In considering valvotomy for the relief of mitral stenosis we are too inclined to concentrate our attention on the valve cusps, forgetting that they are but one part of the valve mechanism. Although the complex nature of the valve mechanism is well known it seems to be largely ignored in dealing with the diseased valve, which is often approached as merely a fibrous, obstructing diaphragm with a small hole that must be made larger. The popular conception of the valve in mitral insufficiency seems to have no logical or scientific basis and is wholly unsatisfactory.

The valve mechanism extends over a distance of some $5 \mathrm{~cm}$., and a lesion may affect all parts of it or one part more severely than another. A lesion at any level can seriously interfere with the mechanism, and it is not always the actual valve cusps that are most seriously affected.

\section{The Normal Mitral Valve}

The normal mitral valve consists of the atrio-ventricular fibrous ring to which the cusps gain their attachment, of the two cusps, and of the papillary muscles with their chordæ tendineæ. The two cusps are anteromedial and posterolateral, being so arranged that the axis of the valve orifice is directed obliquely forwards from right to left (Fig. 1, 18, and 22).

The anteromedial or aortic cusp is much the larger and the more important in that during ventricular systole it receives a great part of the stream of emergent blood which it prevents being driven back into the left atrium and helps to direct into the aortic outlet.

The posterolateral cusp fulfills a secondary and supporting part in the closing of the mitral orifice in ventricular systole.

The papillary muscles are typically two in number and lie opposite the intervals between the valve cusps; they arise from the ventricular wall at about the junction of the apical and middle thirds, one being anterolateral and one posteromedial. Both muscles are situated in the lower inflow portion of the left ventricle; the anterolateral one arising from the concavity of the anterolateral wall of the

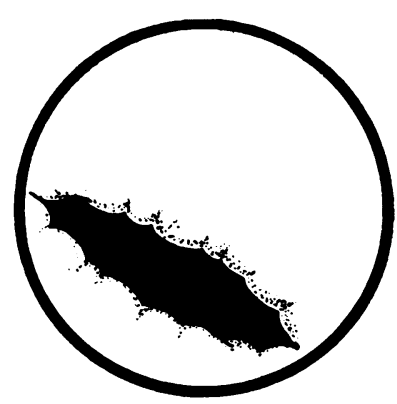

Fig. 1. - Diagram of the arrangement of the mitral cusps. 
ventricle and the posteromedial from the junction of the septal and posterior surfaces. Each muscle may be a single papilla or may be split to a greater or lesser degree so that it is either notched at its apex, deeply grooved along its sides, or bifid. Extra muscles may exist. Rusted et al. (1951) have recently analysed the arrangement of the paillary muscles in 250 hearts.

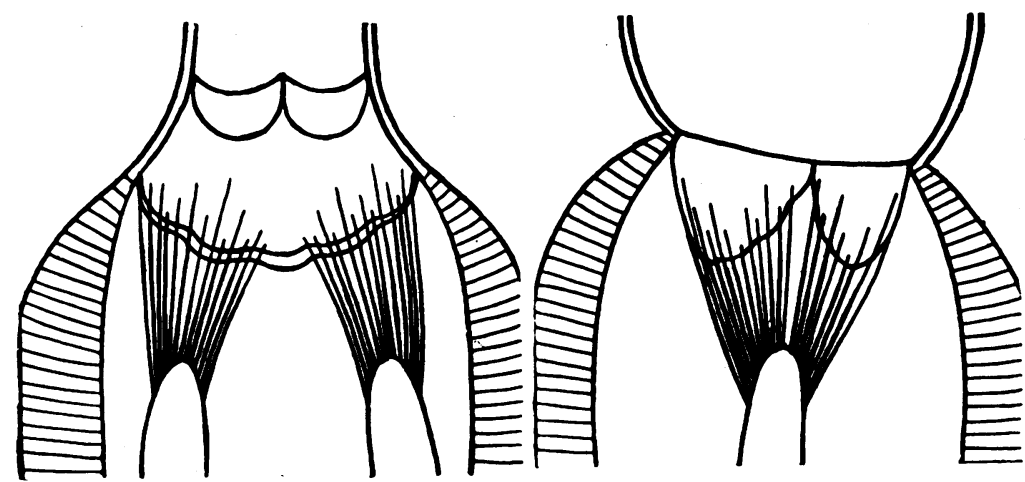

FIG. 2.-Diagram of the arrangement of the papillary muscles and chordæ tendinea. Each muscle and its tendons controls the corresponding half of the opposing cusps.

The chorda tendinea pass from each papillary muscle to gain attachment to both valve cusps in such a way that the anterolateral muscle and its tendons control the anterolateral half of the valve, and the posterolateral muscle and its tendons control the corresponding posterolateral half .(Fig. 2, 3, and 5). The chordæ tendineæ are of three orders, according to Quain (1929).

(1) Those which are inserted on the free edge of the cusps. They are numerous delicate threads which arise from the other cords near the cusp margin, and often form a fine network before they are attached to it.

(2) Those which are inserted at intervals on the ventricular surface of the cusp near its free edge,

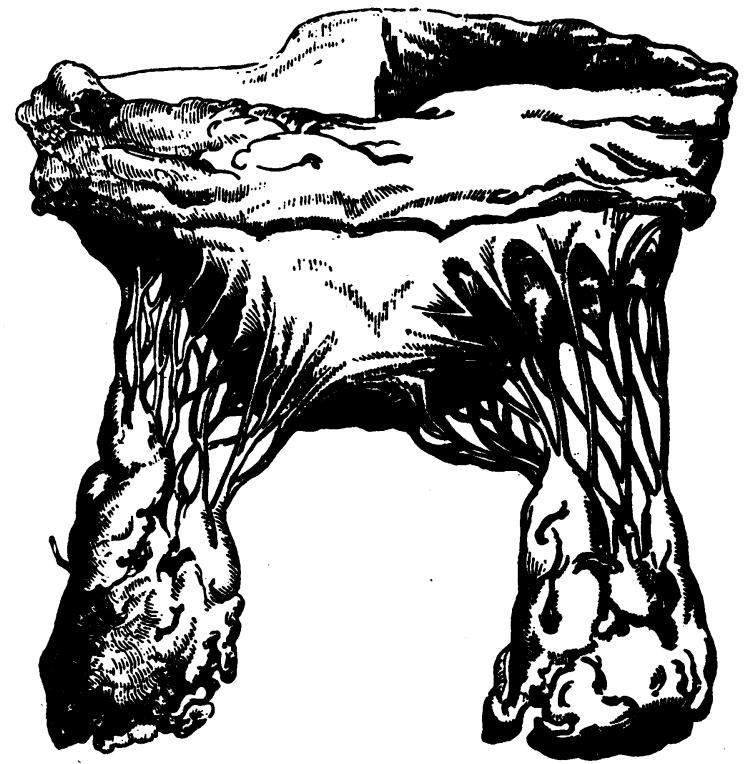

FIG. 3.-The mitral valve. Reproduced from an article in the Guy's Hospital Reports, by T. Wilkinson King, 1840. which they pass over to the attached border. They are distinctly thicker than the chordæ of group 1, and those attached to any one cusp are derived from two different papillary muscles or from one papillary muscle and the wall of the ventricle.

(3) The short, broad fibres that stretch across the perivalvular groove from the ventricular wall to the under surface of the cusp near its base and run along the cusp a short distance towards its free margin.

\section{The Critical Areas of Tendon Insertion}

Although the arrangement of the chordæ tendineæ can be correctly described in this fashion, the total picture presented is too complex - too complete-for practical purposes. It needs simplification. Study of the arrangement has impressed me with the essential importance of the direct or primary attachment of the tendons.

The primary attachments are two on each 
cusp, being situated about $2 \mathrm{~cm}$. apart; these I have termed the critical areas of tendon insertion, for reasons which will become apparent later.

These areas are depicted in Fig. 4 and 5 and are seen to be formed by those tendons that arise from the very summit of the papillary muscles and gain the most direct attachment to the valve cusps. These tendons are often slightly thicker and stronger, and clearly must exercise the most powerful selective action on the cusps since they are in the line of the direct pull of the papillary muscles. The more obliquely placed tendons which gain insertion on each side are of a secondary supporting nature.

The disposition or shape of the cusps is such that there exists, fundamentally, a distal or central horizontal portion and two lateral or receding oblique portions. The critical areas of tendon in-

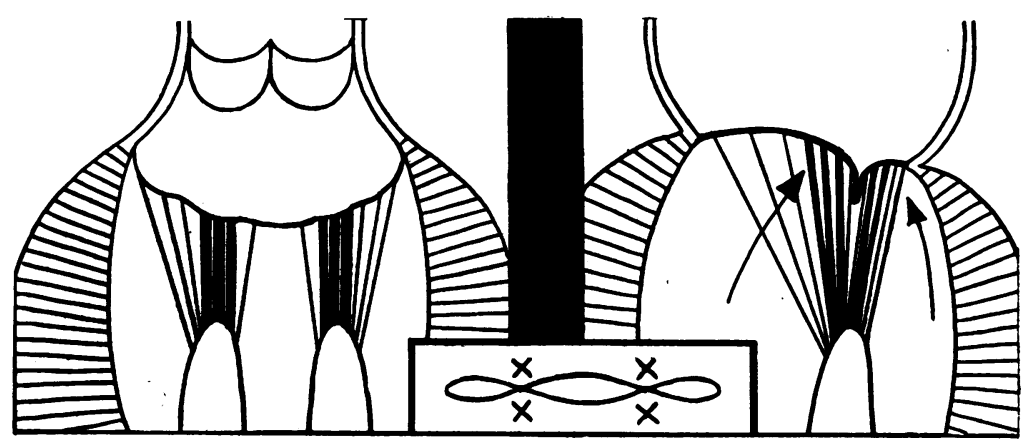

Fig. 4.-Diagram to show the probable mode of closure of the mitral cusps. The thicker chordæ tendineæ are those in the direct line of pull from the papillary muscle to the cusps. The small inset indicates the critical areas of tendon insertion thus formed; in these areas the cusps are held most tightly together.
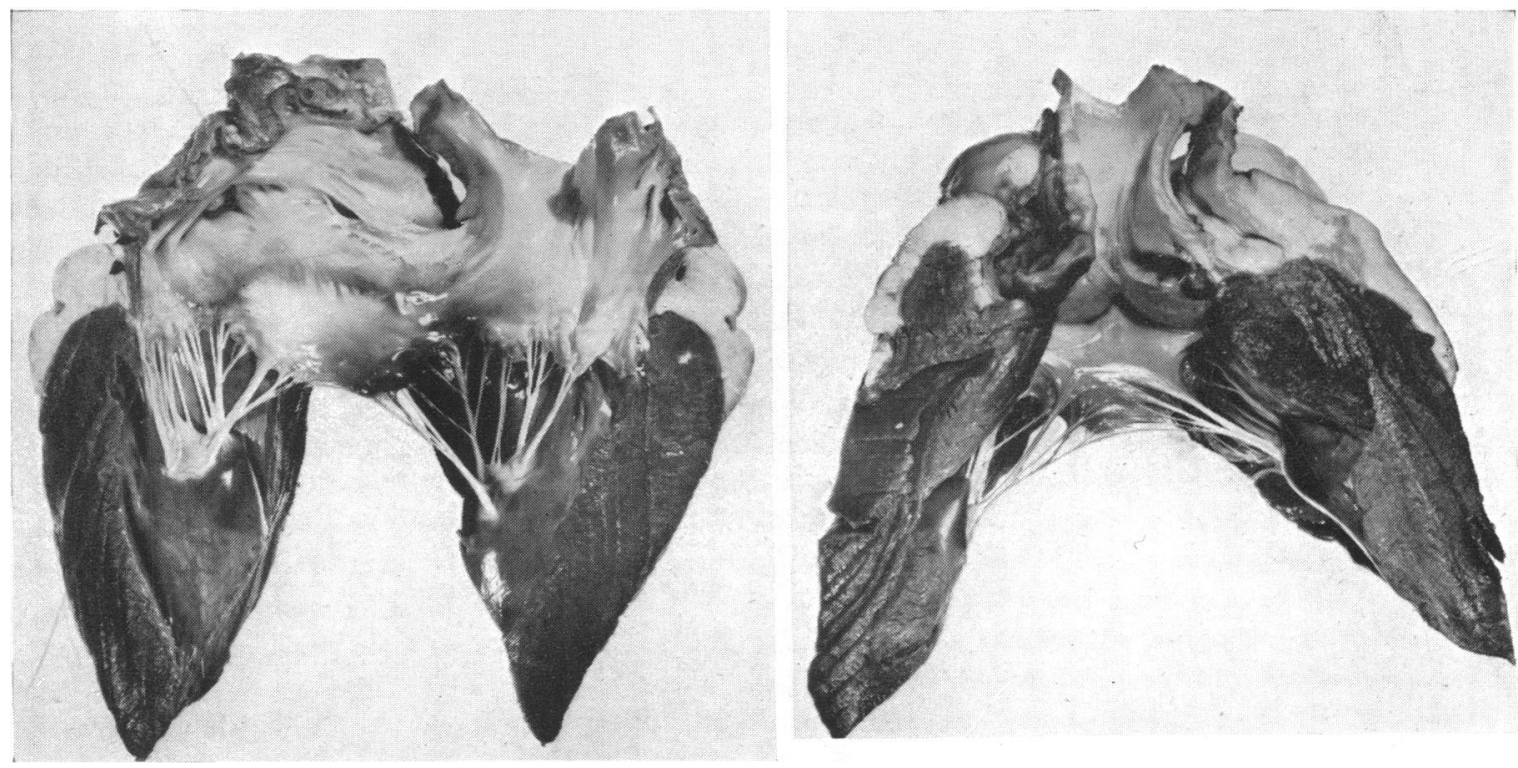

FIG. 5.-Photograph of bullock's heart opened to show the mitral cusps. The arrangement of the tendons from each papillary muscle controlling half of each cusp is well shown. The large, prominent cusp is the anteromedial or aortic, and the critical areas of tendon insertion should be noted with the central blood pathway between. 
sertion are at the junction of the horizontal part and the lateral receding parts of the valve cusps. Most of the oblique or secondary tendons are inserted in relation to the lateral parts of the cusps; fewer pass medially to what may be termed the central pathway of the valve (Fig. 3 and 5). This is especially so in the case of the anteromedial cusp. It is true that the shape of the free edge of the cusps may be described as semicircular or semi-ovoid, but the above suggested resolution into a somewhat arbitrary transverse or horizontal distal central portion and the two lateral receding portions is of great practical importance and, I think, aids clarity of understanding.

\section{The Closure of the Normal Mitral Valve}

Although the mode of closure of the mitral valve may appear to be fairly obvious and simple, it is a good policy to take nothing for granted but to re-examine the existing conceptions from time to time. Actually, there is room for considerable difference of opinion in the exact mode of closure of the valve.

It is almost certain that the two cusps come together along their opposing surfaces, being driven into this position by the rise in pressure during ventricular systole (Fig. 4). The anterior cusp is $15-18 \mathrm{~mm}$. long at its middle part and the posterior cusp is $10-12 \mathrm{~mm}$. The extent of their probable contact can be judged from the observation (Quain, 1929) that the area of the atrioventricular orifice is $855 \mathrm{sq}$. $\mathrm{mm}$. in a man and the surface area of the two cusps is $1868 \mathrm{sq}$. $\mathrm{mm}$. The proportion of valve area to orifice area, therefore, appears to be from $1: 1 \cdot 5$ to $1: 2 \cdot 2$. The overlap may, in fact, be more than this, because when the ventricle contracts the A-V ring is reduced in circumference and the area of the orifice is correspondingly reduced.

On the other hand Quain does not state the conditions under which these measurements were obtained, although presumably in the cadaver, and we must make allowance for much variation in the degree of contraction and dilatation of the heart and mitral orifice that may be present, whether caused by disease or by rigor mortis affecting the heart muscle. Nature is always prodigal in her reserve and it may well be that the overlap described above pertains to quiet resting conditions of the healthy heart, but is greatly lessened during exercise or illness, especially when the heart muscle is affected by the disease.

A possible alternative mechanism of closure is that the orifice is closed entirely by the anteromedial or aortic cusp forcing the much smaller posterolateral cusp against the posterior wall of the ventricle (Fig. 6). It is doubtful if this is the usual mechanism, but it may well happen sometimes; it is unlikely to occur. if the A-V ring is at all dilated.

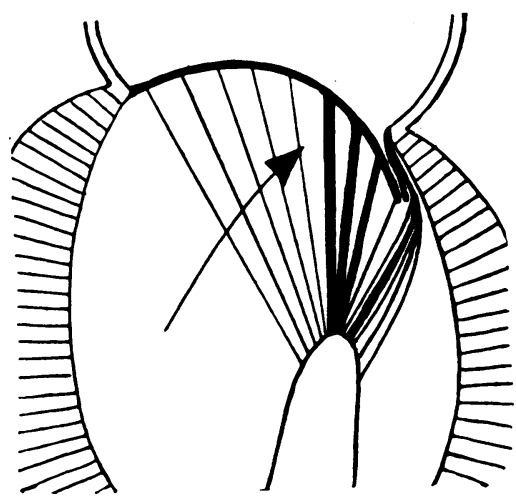

Fig. 6.-Diagram to show a possible alternative mode of closure of the mitral valve in which the posterolateral cusp is forced against the wall of the ventricle by the anteromedial cusp. In systole the inflow portion of the left ventricle is tightly contracted so that its cavity is almost completely obliterated, but sufficient space remains postero-inferiorly for the hydrostatic pressure to reach the ventricular aspect of the posterolateral cusp and force it away from the wall of the ventricle. The greater part is in contact with the opposing surface of the aortic cusp and its "free " area must be small. When the finger is introduced into the left atrium during an operation for mitral stenosis, the anteromedial cusp is usually very easily felt billowing upwards into the atrium like a sail filled with the wind; it is much more difficult to feel the posterolateral cusp, and, indeed, its presence has often rather to be assumed by judging the distance that lies between the actual mitral orifice and the posterior part of the A-V ring.

Lutembacher (1950) describes the mechanism of closure as a bunching up in which the valve cusps, the chordæ tendineæ, and the papillary muscles come together in such a way that the closure of the orifice is aided and secured by an actual interlocking or interopposing of these structures, and he describes and depicts specimens in such a way as to indicate that the partly cockled-up mitral orifice in mitral stenosis actually occupies grooves on the papillary muscles. 
This is a conception reached by inspection of the dead contracted heart; from what the finger feels when inside the contracting heart it cannot be a true one. I have felt the mitral valve functioning on some 150 occasions and the aortic cusp at least has always been forced or billowed towards the atrium; it has never been gripped or bunched up within the orifice.

Although it is difficult to feel the posterolateral cusp billowing out, it would be strange if it did not do so in conformity with the aortic cusp, for the very presence of the musculo-tendinous mechanism indicates that this is the action of the cusp in systole. It cannot fail to be forced upwards and backwards in this manner unless it is entirely protected from the high ventricular systolic pressure by complete apposition with the posterior wall of the ventricle.

There is little doubt that the aortic cusp is the main factor in effective closure of the orifice and the posteromedial cusp occupies a subsidiary or adjuvant function in sealing a narrow and probably variable posterior crescent of the orifice. The variability of its apposition with its fellow cusp in varying degrees of cardiac activity or dilatation has already been mentioned.

According to Quain the distance between the apex and the base of the left ventricle does not shorten during contraction of the ventricle; the atrioventricular region moves upwards and backwards, but the length of the cavity remains constant. This makes it easier to understand how the comparatively small contraction of the papillary muscles is able to ensure efficient closure of the valve. Actually, all that is needed is quite a small tensing of the chordæ tendineæ to prevent the cusps being blown open into the atrium. The apposition of the cusp surfaces ensures their watertight closing, but the pressure-resisting mechanism comes from the musculo-tendinous support and its neuromuscular co-ordination with ventricular systole. The mode of insertion of the tendons from one papillary muscle to each of the opposing cusps increases the efficiency of the mechanical closure of the valve.

The important, indeed fundamental, part played by the papillary muscle mechanism was dramatically, albeit tragically, emphasized for me in one unfortunate operative experience (Brock, 1950). After dividing the stenosed orifice in a case of mitral stenosis I tried to reach the aortic valve by passing the index finger around the aortic cusp of the mitral valve. I had just reached the valve with the finger-tip when something gave way and immediately severe mitral regurgitation occurred; a powerful regurgitant stream of blood could be felt entering the atrium, the walls of which could be seen to distend freely with each ventricular systole. Clearly the high ventricular pressure was being transmitted directly to the left atrium. I thought that the aortic cusp had been torn transversely across its substance. The patient, unable to tolerate this severe acute mitral incompetence, died some 48 hours later and autopsy revealed that the anterolateral papillary muscle had been torn from its ventricular attachment; the simple mechanical apposition of the two cusps had not been enough to prevent the severe and fatal regurgitation.

During ventricular diastole the papillary muscles and the tendons are lax and the cusps float open before the stream of blood from the atrium. During ventricular systole the valve cusps are flung tight together and the papillary muscles and tendons become taut and straight; the maximum, the most powerfully supported, closure must occur in relation to the critical areas of tendon insertion already described. At the height of systole the tendons passing from the summit of each papillary muscle direct to these two critical areas on the valve cusps must be tense and parallel and very close to one another (Fig. 4); in contrast with during diastole when they are lax and directed outwards towards the wide open margins of the orifice. At these two critical areas the cusps must be held together very tightly indeed; the significance of this will become apparent when we consider the state of the diseased valve. Sokoloff et al. (1950), as a result of a study and survey of the chordæ tendineæ in 200 hearts of all ages, have shown that the more centrally placed chordæ of the anterior cusp are thickened and more powerful in every heart and this can be noted at all ages and in animals (bovine) when rheumatic infection can be excluded. The changes are less marked in the chordæ of the posterior cusp, as would be expected.

The size of the mitral orifice. I have always been intrigued by the difference in size between the A-V orifice and that of the aorta or pulmonary artery. The explanation that first suggests itself is that this is related $2 \mathbf{L}$ 
to the lower pressure in the atrium. This may be so except that nature could just as easily have made the atria slightly more powerful without interfering with any venous reservoir or volume-regulating function they may possess. After all the blood has only to be expelled into the lax ventricular cavity during the long diastolic filling period; the atria do not have to maintain a systemic or even a pulmonary blood pressure such as the ventricles must do.

I do not believe that the real difference in size between the atrial and the aortic orifices is anything like so great as appears. The explanation is that only a part of the A-V channel functions as a true pathway for the blood; this soon becomes apparent when the mechanism of the normal mitral valve is considered more closely.

Quain gives the size of the aortic and the mitral orifices in $\mathrm{mm}$. as follows:

Aortic orifice: $26 \mathrm{~mm}$. in diameter, $530 \mathrm{sq} . \mathrm{mm}$. in area

Mitral orifice: $32 \mathrm{~mm}$. in diameter, 855 sq. $\mathrm{mm}$. in area

We are thus faced with an apparent difference in size which is indicated by the diagram shown in Fig. 7 . The mitral orifice has not been depicted as a circle in spite of the figures given above, for in fact it is usually not circular during life.

If, instead of simply superimposing the two " orifices" in this way, we consider them in the form shown in Fig. 8, we obtain a different conception which is best explained by developing the diagram further to present the basic structure of the mitral valve already mentioned. That is, a distal horizontal or central portion and two receding lateral portions; at the junctions of the central and lateral portions are the critical areas of tendon insertion (Fig. 8 B).

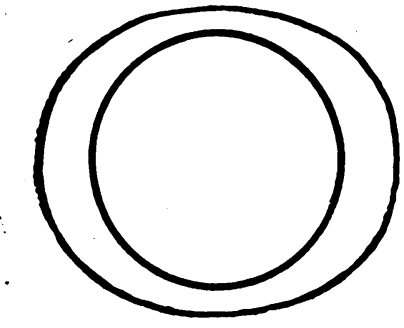

FIG. 7.-Diagram to contrast the relative size of the mitral and the aortic orifices.
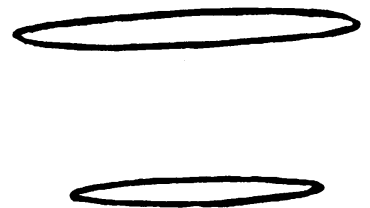

A

FIG. 8.-Diagram to illustrate the suggested mode of construction of the mitral pathway.

We may now return to a diagrammatic representation of the mitral orifice from above (Fig. 9) with the valve in the open and in the closed state. Although the orifice may be thought to open as a simple oval, it will be seen that this is, in fact, not so. The part of the valve orifice that matters is what I would term the central channel and it is formed by the opening of the distal, horizontal, central portions of the cusps. The receding lateral portions serve merely as hinges, allowing the central portions to open and close. Indeed, the two "lateral" parts of the valve channel on each side of the central channel are largely filled in, when open, by the numerous chordæ tendineæ radiating, fan-wise, upwards and outwards from the papillary muscles (Fig. 3). The tendons passing to the borders of the central channel are fewer and are disposed so as not to interfere with the blood pathway.

It will thus be seen that the effective orifice of the mitral valve is much smaller than would at first appear, and is much more closely related to that of the aortic orifice. The apparent difference in size is due entirely to the essentially different mechanisms in the opening and closing of the aortic valve and the mitral valve. McMillan et al. (1952) have recently demonstrated that the functional aortic outlet at the valve level is triangular and not actually circular.

\section{The Diseased Mitral Valve}

It is usually taught that in the milder forms of rheumatic infection the edges of the mitral cusps become thickened and distorted and some incompetence results; and that with a more severe 
infection the valve cusps adhere, the orifice becomes contracted, and stenosis follows. Examples are depicted in text-books of valves, said to be incompetent, in this lesser state of thickened, distorted edges. In this way many students gain the impression that mitral incompetence results from a mild rheumatic valvitis, and stenosis from a more severe attack. This is an erroneous simplification; a high degree of mitral stenosis can be caused by a relatively mild attack of rheumatic valvitis; in contrast, true mitral incompetence is usually caused by the most severe grades of damage to the valve. The condition of the thickened. deformed edges with no fusion of the cusps is, almost certainly, of little or no functional significance.

Study of diseased mitral valves teaches that considerable varieties and degrees of valvitis occur. Although a clinical state of "mitral stenosis" may be present, the actual condition of the valve mechanism varies greatly from case to case and with corresponding differences in the degree of benefit that can follow operation. The valve orifice may be equally small in two cases, but in one the valve cusps may be thin and almost normal and a successful valvotomy will restore an almost normal valve; in the other the whole valve structure may be so altered, so rigid and fibrous, that no more than a partial restoration of function is possible.

It is necessary to draw attention to the loose use of the terms mild or severe mitral stenosis. The picture often conveyed, and intended, by such expressions is that the actual degree of contracture of the orifice may be slight, moderate, or severe. This is not in accordance with operative experience; the mitral orifice in stenosis is almost always a small oval about $1 \mathrm{~cm} . \times 0.5 \mathrm{~cm}$.; in a small percentage of cases it may be very much smaller and is then usually circular, as little as $0.4 \mathrm{~cm}$. in diameter.

It is, however, not possible to explore case after case and observe the almost standard small orifice, $1 \mathrm{~cm} . \times 0.5 \mathrm{~cm}$., without being impressed by its occurrence and significance. The same small orifice is found in cases with mild symptoms or with severe symptoms. It is not the mitral stenosis that is mild or severe; it is the resulting
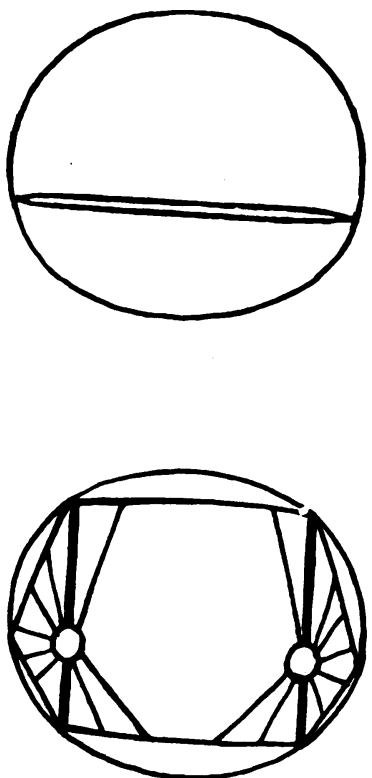

Fig. 9.-Diagram to show the mode of action of the mitral cusps. The true functional pathway is the central portion; the lateral portions serve as hinges allowing the central part to open and close. The thickened chordæ tendineæ indicate thecritical areas of insertion; lateral to these the pathway is closed by the lattice work of the supporting oblique tendons. Note the effective central pathway is much closer in size to that of the aortic pathway; cf. Fig. 7.

disability. The anatomical variation in the size of the hole is slight; the clinical variation of symptoms is considerable. It would seem that a certain minimal size of valve orifice must be reached before clinical disability is likely.

This has an important practical bearing for two reasons. First, just because a patient has early symptoms of mitral stenosis it is not to be assumed the orifice is only mildly contracted; at operation it will be found little or no different from that found in a severe case. The patient with mild symptoms can expect to receive just as much mechanical relief by valvotomy as one with severe symptoms. Second, the anatomical occurrence of this virtually "standard" type of orifice in mitral stenosis demands an explanation based on sound pathological anatomy.

\section{The Mechanism of Production of Mitral Stenosis}

Rheumatic inflammation occurs firstly and chiefly along the margins of the valve cusps; if the cusps remain separate and only the margins are affected, the final result is merely some permanent thickening and mild distortion of the edges of the cusps, a condition of no functional importance.

The significant event in the production of mitral stenosis is the fusion of the valve cusps and this occurs, fundamentally, at the two opposing critical areas of tendon insertion (Fig. 10A). It must be 
emphasized that in an appreciation of this simple fact lies the correct understanding of the production, the anatomy, and the technical operative treatment, of mitral stenosis.

It is in these areas that the inflamed cusps are held most tightly together in systole; once cross adhesion has occurred, important secondary changes follow, for the hinge-like action of the lateral parts of the valve cusps is at once lost. In other words, the opening of the central pathway in diastole is prevented; the valve cusps cannot move apart, held as they are by the cross fusion at these critical sites. The central pathway-functional lumen of the valve-must inevitably remain partly open if life is to continue, but its size is inevitably no more than a shallow oval formed between the two areas of adherence at the critical points (Fig. 10B).

To the outer side of each critical area, i.e. on each side of the central pathway, the valve lumen is now functionless, it does not form part of the main blood channel from atrium to ventricle, and

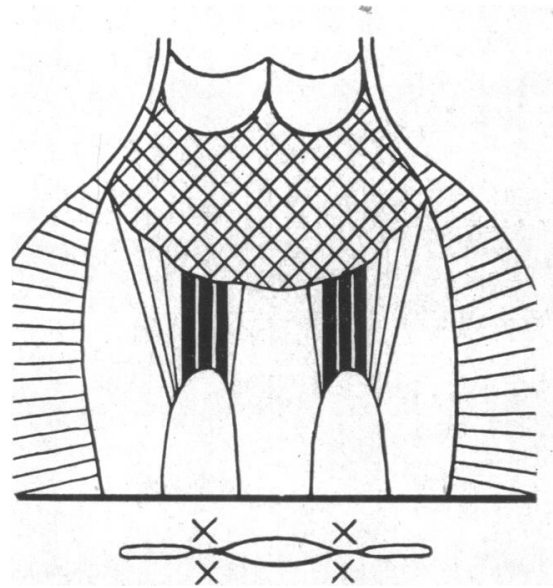

A

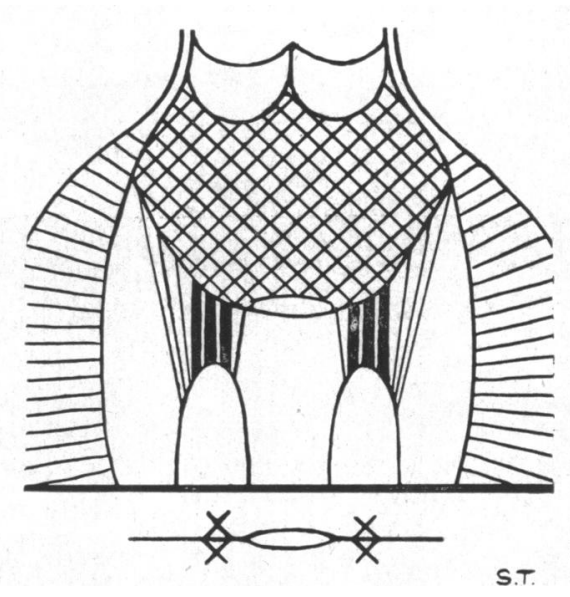

B

FIG. 10-Diagram to show suggested mode of adherence and fusion of the cusps and consequent production of mitral stenosis. In $\mathrm{A}$ the inflamed cusps adhere first of all at the critical areas. In B complete cross fusion of the critical areas has occurred, and also secondary adherence of the commissures.

as already pointed out, it really exists only to allow complete opening of the central part of the valve lumen or pathway in diastole. Once the two lateral components are prevented from opening in this way by the cross fusion of the critical areas of tendon insertion it is inevitable that they should completely fuse together since there is no powerful direct stream of blood to keep them apart. In this way the two " commissures" are formed; i.e. the cusp margins are fused from the atrial ring up to and including the two critical areas of tendon insertion (Fig. 10B).

The commonly accepted notion that stenosis arises from progressive fusion of the cusps, beginning at the periphery and extending inwards, is quite erroneous. Cases of mitral stenosis with partial lateral adherence of the cusps with non-adherence of the "critical " areas just do not occur. It is true that the orifice may be eccentrically placed and one commissure may be much shorter than the other or both may be very short, but this is due to variation in the focal incidence of the infection which may produce a more severe degree of inflammation in one place and therefore greater local contracture.

Once cross adhesion of the critical areas and secondary adhesion of the commissures has occurred, a state of mitral stenosis inevitably results. The degree of stenosis must clearly depend on the size of the oval aperture that is subtended between the fused critical areas. In the earlier stages, or in cases in which the valvitis is mild, this central lumen may be rather larger than in other circumstances, but is never likely to be more than about $1.5 \mathrm{~cm} . \times 0.75 \mathrm{~cm}$. 
If the valvitis is severe, recurrent, or chronically smouldering, this central lumen is likely to become rapidly much smaller and with correspondingly more rigid margins. Symptoms may then occur early.

If the valvitis ceases quickly and the patient is left with a small functional oval lumen some $1 \mathrm{~cm}$.$1.5 \mathrm{~cm}$. in length and with fairly supple margins, although stenosis is present, symptoms may be completely absent. With a healthy muscle there is little doubt that considerable stenosis of the central pathway of the mitral valve can be readily compensated for. Symptoms could appear if the muscle begins to weaken, but the more likely cause is a steady diminution in the size of the valve lumen until it reaches what might be termed the minimal effective area. This seems to be the small oval aperture most commonly seen, some $1 \mathrm{~cm} . \times 0.5 \mathrm{~cm}$; if the lumen becomes smaller than this graver symptoms can only be forestalled by a correspondingly greater increase in the power of the atrial muscle and the increased risk of its failure.

The steady diminution in size of the central lumen towards the minimal effective area, if not caused by actual rheumatic infection, is inevitable from the daily wear and tear of the blood stream passing through the narrowed orifice, especially as the wear and tear or friction is steadily increased by the stronger flow of blood brought about by the more powerful contractions of the partly obstructed left atrium. By the deposition of platelets and fibrin the edges become thicker, more fibrous and therefore more contracted and rigid and the orifice correspondingly smaller; verrucose projections and even calcified plaques and masses add further to the obstruction. This progressive and relentless shrinkage of the functional central lumen over the course of the years is one main reason why the appearance of symptoms in mitral stenosis is closely related to increasing age and is commonest between 30 and 40 years. Clearly the condition of the atrial muscle is also important in this connexion.

Just as the edges of the valve opening are exposed to the wear and tear of the blood stream, so are the chordæ tendineæ in the direct line of pull from the papillary muscles, as these inevitably form part of the banks confining and directing the stream of blood issuing from the stenosed orifice. It would therefore be expected that these chordæ should show extra evidence of thickening all along their length. This is indeed so and Sokoloff et al. (1950) have drawn attention to the occurrence of sclerotic changes in these central chordæ tendineæ, especially of the anterior cusp, in the heart of middle-aged subjects who were not rheumatic; the sclerosis is due to deposition of subendocardial collagen and affects the whole length of the chordæ and more particularly the central ones which are more exposed to the mechanical action of the blood stream. Magarey (1951) has also written of this.

\section{Mitral Stenosis with Minimal Valvitis}

The basic mechanism of valve fusion, beginning with cross adherence of the critical areas and extending by more gradual secondary narrowing of the central pathway, is seen most clearly in cases in which the rheumatic infection has been confined almost entirely to the valve margins. The patient's symptoms may be severe ; the central orifice characteristically small, $1 \mathrm{~cm} . \times 0.5 \mathrm{~cm}$. or even less, its edges firm and fibrous; in other words the stenosis is severe. The condition of the valve cusps themselves, however, shows that the original rheumatic infection was not severe; or at least did not affect the whole valve cusps but chiefly the margins. Although the edges of the central orifice may be firm or even dense, the fusion of the critical areas is not densely fibrous, the commissures are often very lightly fused, and the actual valve cusps are thin, supple, and almost normal. Moreover, the chordæ tendineæ are thin and separate and once the two cusps have been separated (by splitting or cutting) as far as the A-V ring on each side, an almost normal valve mechanism is restored.

It is noteworthy that a patient can have such a severe disability, eventually fatal, from a simple cross fusion of the cusps following what must have been a mild form of valvitis and that this great disability can be quickly relieved by a short and simple operation. 


\section{Mitral Stenosis with Severe Valvitis}

In the more severe grades of rheumatic valvitis the process is no longer confined to the margins but spreads to involve the cusps, the chordæ tendineæ, the A-V ring and even the papillary muscles. The cusps become generally thickened and fibrous so that they constitute a rigid or semi-rigid fibrous diaphragm with a small rigid orifice. Calcification may also be added, either in the form of light surface deposit or thick plaques or exuberant craggy masses.

The chordæ tendineæ become thickened, matted together, and shortened; in extreme cases the fibrous reaction extends down to involve the papillary muscles, and the chordæ may then be so shortened that the papillary muscles are almost directly fused with the valve cusps themselves, only a short thick fibrous mass intervening (Fig. 11, 12, and 13). The papillary muscle and tendons may even adhere to the wall of the ventricle. Occasionally calcification extends from the valve cusps and the orifice, down the chordæ tendineæ as far as the papillary muscles, so that a narrow calcified channel is formed. The fibrosis may also involve the A-V ring, which becomes smaller and rigid, and in some cases actually calcified.

These facts are, of course, common knowledge, but it is necessary to consider more critically the precise effect on the chordæ tendineæ. The most important change occurs in those tendons directly inserted into the critical areas.

The primary fusion of the cusps in these areas has been described; in mild forms of inflammation the chordæ are not fused, or only lightly, so that if the adherent cusps are divided the valve orifice can immediately open widely or will do so if the lightly fused tendons are separated with the finger. When, however, the valvitis is severe, the primary groups of tendons inserted into the critical areas become fused firmly to one another and cross fusion also occurs between the sets on each side of the valve cusps. Thus, to the fusion of the cusps or commissures is added a dense fusion of the

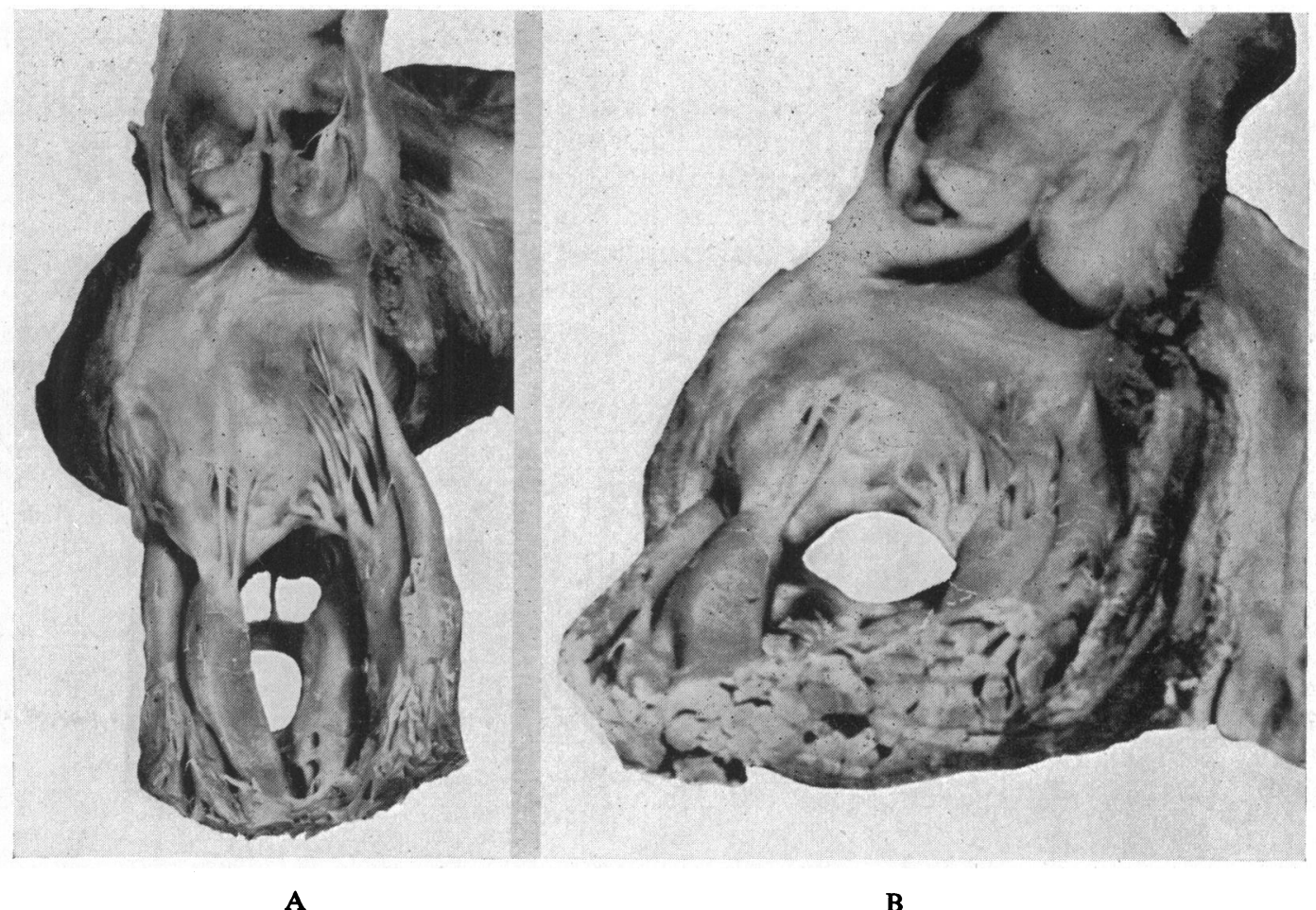

FIG. 11.-Photograph of stenosed mitral valve to show the matting and shortening of the chordæ and, in the view from below, (B), the narrowed residual central pathway between the two flanking, fused critical areas of tendon insertion. 

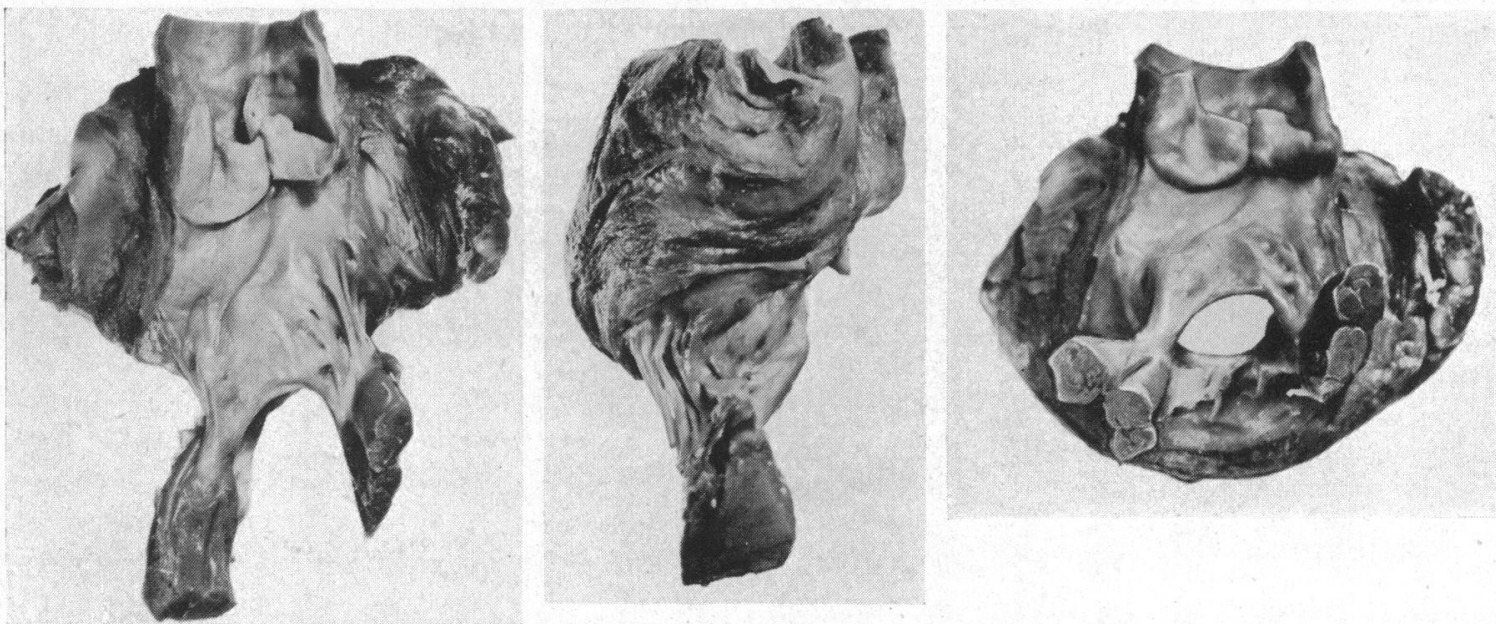

Fig. 12.-Photograph of a severe form of mitral stenosis in which the cusps are very densely fibrous and the fused chordæ tendineæ at the critical areas form a thick solid mass of fibrous tissue more than $1 \mathrm{~cm}$. in thickness in each direction. At operation it was not possible to enlarge the stenosed orifice further than this strong barrier on each side. Even if the barrier had been cut through, the fusion down to the papillary muscles would have prevented the cusps from opening. Carrying the incision round the fused tendons would have destroyed the support of the cusps and caused severe regurgitation. It is in this type of valve that secondary narrowing of the orifice, i.e. recurrence, is inevitable, although it may take some time to become of clinical importance.
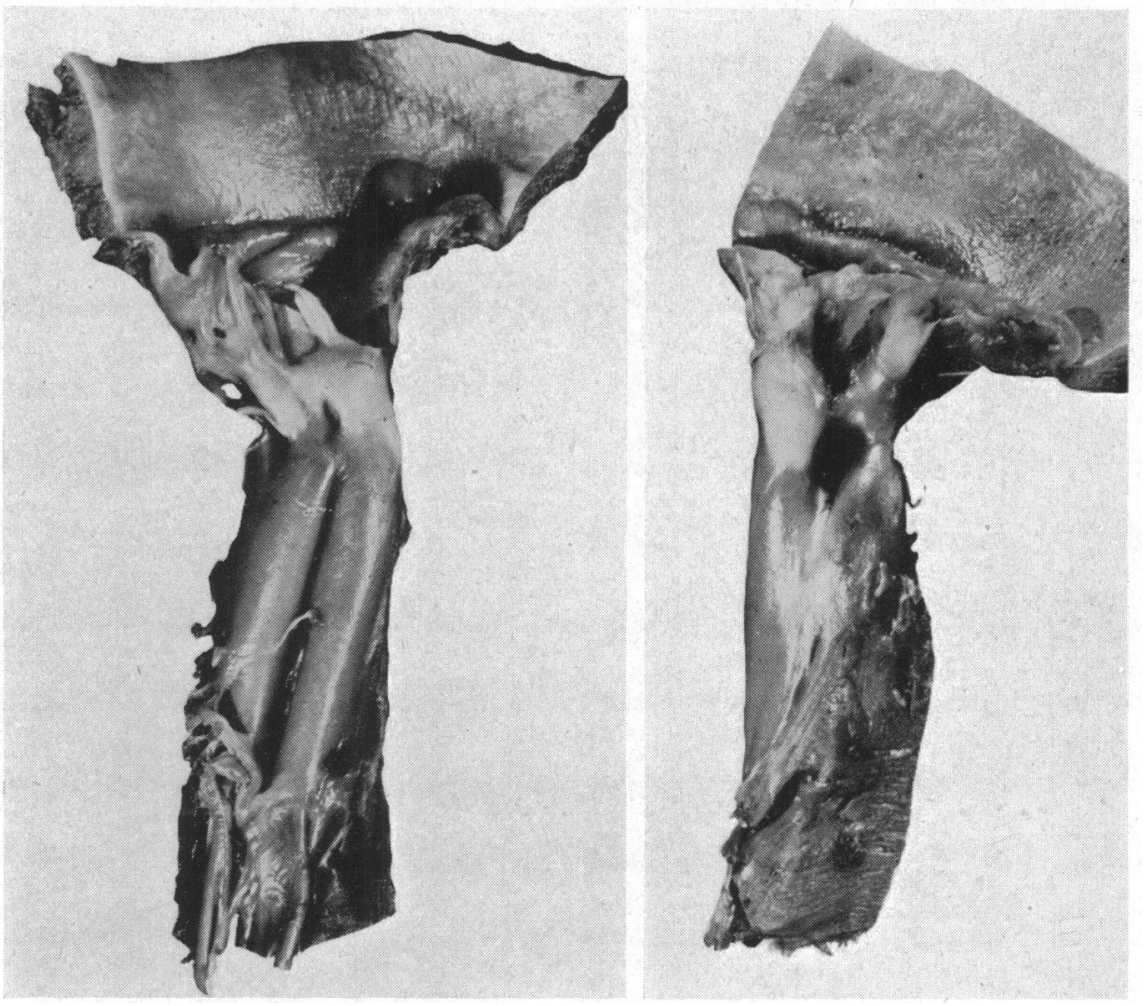

FIG. 13.-Photograph of a grossly scarred and virtually disorganized valve. Such severe changes and dense fusion make a condition that is virtually inoperable: 
tendons. Even if the fused cusps are cut apart the valve orifice still cannot open because it is held firmly by the fused and interfused chordæ. These may form a solid, thick barrier or column as much as a centimetre or more in both width and thickness (Fig. 12 and 13). This fusion of the primary tendons inserted directly into the critical areas is further reinforced by inclusion of the more obliquely placed tendons so that these now pass straight up to the critical areas and then incline outwards along the under surface of the cusps almost like the fan tracery of Gothic architecture radiating from the supporting columns of the roof (Fig. 14). It is clear that when such a thick, fibrous, fused mass is formed it constitutes a grave obstacle to the effective surgical relief of mitral stenosis. Moreover, the valve mechanism is very badly damaged, although not entirely ruined if incompetence is absent or slight.

Fortunately the more severe grades of valvitis may not always affect the whole of the valve mechanism. Indeed, it is quite common to find that the brunt of the inflammation has fallen chiefly on one part. This may be either the medial or the lateral commissure and the adjacent part, more commonly the medial than the lateral. One commissure may be short and occupied by an exuberant, craggy, calcified mass with dense fusion of the chordæ, while the other is still only mildly affected. It is noteworthy that one effect of valvitis may be to lengthen the cusps, especially the anterior or aortic cusp, as a result of extension of exudate and its organization along the chordæ

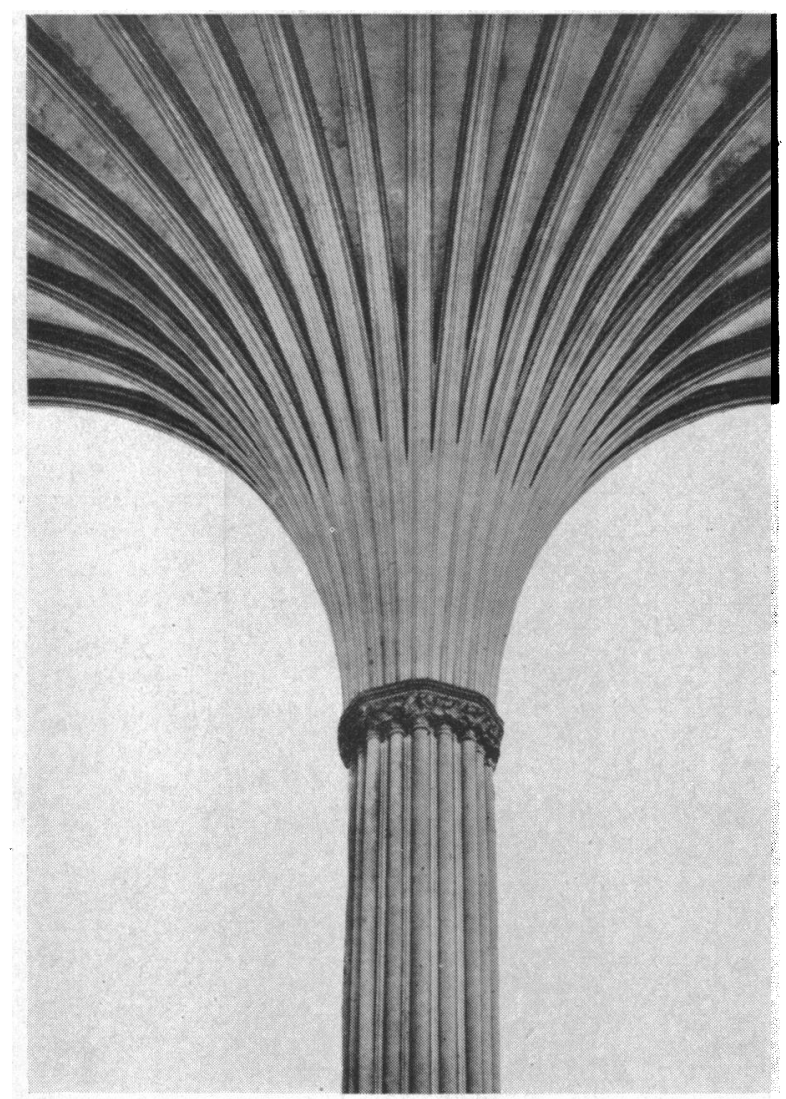

FIG. 14.-A Gothic column with fan tracery to recall the solid fusion of chordæ tendineæ and their radiation beneath the cusp. Reproduced by the courtesy of Messrs. Thames and Hudson, from English Cathedrals, by Martin Hürlimanm.

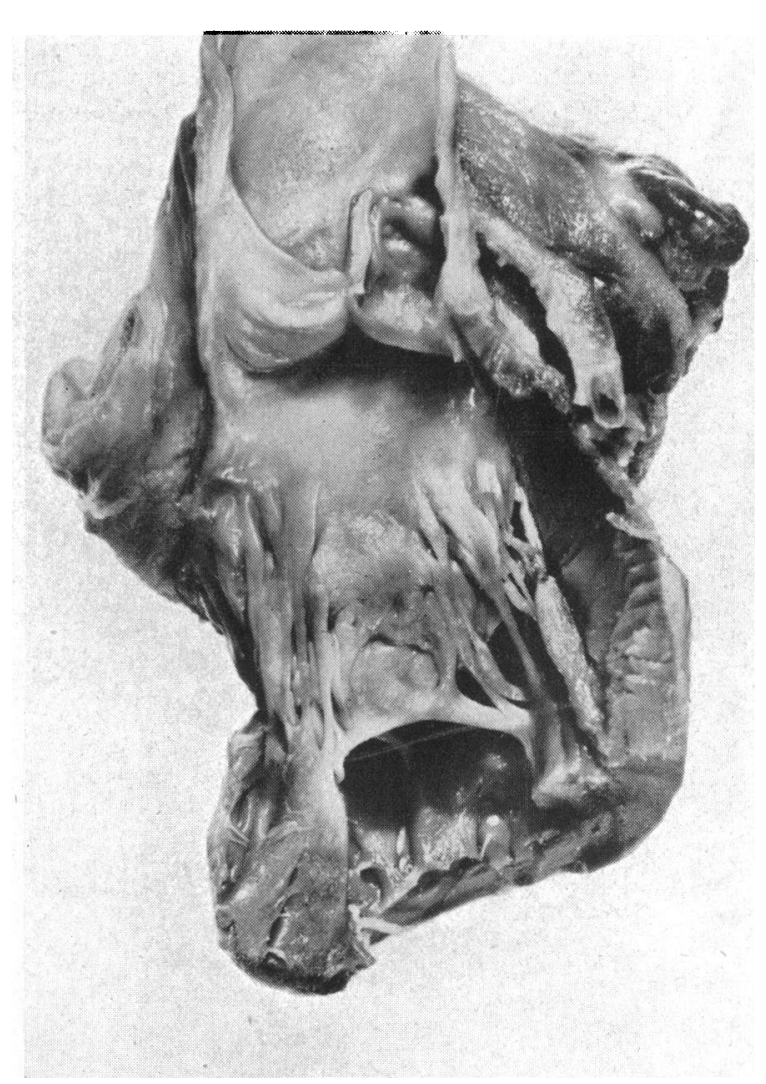

FIG. 15.-Photograph of specimen of mitral stenosis to show the way the aortic cusp becomes lengthened as a result of organization of exudate extending into the chordæ. 
tendineæ from the free margin of the valves (Fig. 15). This process also contributes to the secondary shortening of the tendons (Fig. 11, 12, and 15). It is in contrast to the shortening of the cusps observed in cases of mitral regurgitation.

\section{Mitral Regurgitation}

The diagnosis of mitral regurgitation, formerly made with such confidence, is now accepted as a matter of greater difficulty. The operative treatment is even more difficult. It is obviously essential, in order to make our task easier in these two matters of diagnosis and treatment, to begin with a clear conception of the pathological anatomy of the incompetent valve.

I have already referred to the common error in teaching that a mild rheumatic valvitis, by distorting the edges of the cusps, can cause incompetence at a stage earlier than the production of mitral stenosis. This encourages the idea that mitral incompetence is a milder lesion than mitral stenosis. There is no doubt that this is wrong, both clinically and pathologically. Clinically mitral regurgitation can cause some of the severest forms of cardiac disability. Pathologically it is the result of the severest forms of damage to the valve mechanism, often being associated with complete or almost complete ruining of the valve as a valve. In mitral stenosis, in contrast, even though the degree of obstruction may be severe, the damage to the valve mechanism may be slight and, once the fused valve cusps have been separated, an almost normal valve may be restored. This is never the case with mitral regurgitation.

It is helpful, first of all, to consider what changes may cause the valve to be incompetent, and the six following changes will be considered. Frequently more than one, or even several, of these mechanisms may co-exist, although in varying grades of importance.

(1) A hole or defect in a valve cusp.

(2) Rigidity of the margins of the valve orifice preventing its closure.

(3) Rupture of the musculo-tendinous mechanism so that a cusp is unsupported in ventricular systole.

(4) Shortening of one or both cusps so that they cannot meet and overlap.

(5) Shortening of the musculo-tendinous mechanism so that the valve cusps cannot rise and meet.

(6) Extreme dilatation of the atrioventricular ring leading to secondary relative shortening of the cusps.

\section{(1) A hole or defect in a cusp}

This is not a feature in rheumatic valvitis, but may be caused by ulceration and destruction of the valve in malignant endocarditis. It can also follow ill-conducted surgery when the substance of one of the cusps (especially the anterior) is damaged. A unique, but at the same time informative case is one reported of a young man who sustained a bullet wound of the anterior cusp and died several years later of heart failure from the resultant incompetence.

\section{(2) Rigidity of the margins}

The orifice in mitral stenosis is typically a small oval some $1 \mathrm{~cm} . \times 0.5 \mathrm{~cm}$. In most cases the cusps are sufficiently supple to permit closure, either by overlap or by compression of the opening. If, however, the margins are very fibrous or supported by calcium so as to be quite rigid, then the opening will not close completely in systole and some regurgitation occurs. This may also be favoured if the axis of the orifice is distorted so as to present in an unusual direction, e.g. it may be rotated forwards or backwards so as to favour regurgitation. Even if reflux takes place through the full size of the opening it could not be really significant, and in fact the orifice is often made smaller, even though not completely closed, in systole. In other words the reflux is small and although it may add a systolic murmur to the first heart sound, it adds little if anything to the cardiac disability caused by the stenosis. Moreover, when the fused valve cusps are freed by valvotomy the stenosed orifice loses its rigidity and the suppleness of the cusps is usually enough to correct the insufficiency.

Incompetence from this cause is, therefore, scarcely either a clinical or a surgical problem. 


\section{(3) Rupture of the musculo-tendinous mechanism}

This is a rare occurrence from disease, usually cardiac infarction. Death follows within 24 hours. Smith (1950) mentions 33 reported cases and adds two of his own. An example due to rupture of a papillary muscle at operation was mentioned earlier.

\section{(4) Shortening of the cusps}

The function of the valve cusps is to meet sufficiently to close the mitral orifice during systole; if they are too short to meet and a gap is left between their edges, regurgitation follows. The more severe grades of rheumatic valvitis cause shortening and rigidity of the valve cusps, and hence incompetence. Indeed, it is the cause par excellence of the more severe grades of incompetence which cannot occur merely from a minor affection of the contact margins of the cusps. The normal overlap is so great that considerable damage to the whole substance of the cusps is needed.

This factor of cusps, so shortened as not to meet efficiently, is clearly closely correlated with the two remaining factors, especially the next one.

\section{(5) Shortening of the musculo-tendinous control}

The valve cusps should float widely open in diastole and then in systole are flung up again until the active contraction of the papillary muscles tenses the tendons and holds the flaps secure. If the papillary muscles and tendons are fused into a solid fibrous mass, shortened and densely adherent to the valve, this mechanism is lost. The valve cusps cannot open properly in diastole, neither can they rise properly to close in systole. There is virtually a fibrous ankylosis of the valve mechanism.

The severe grades of rheumatic infection which cause such advanced changes in the chordæ and papillary muscles are just those that cause equally severe rigidity and shortening of the cusps; thus the two factors work together for evil.

\section{(6) Dilatation of the atrioventricular ring}

The cusps of a normal valve being inextensible it follows, at any rate in theory, that if the A-V ring were to dilate sufficiently the cusps would no longer meet and incompetence would result. It is probable that this does occur in rheumatic or other forms of myocarditis and may be the cause of the systolic murmur.

If the cusps are shortened by disease, regurgitation can obviously occur more readily if the A-V ring dilates. It is, therefore, a secondary or adjuvant factor aiding incompetence and, moreover, can form part of a vicious circle in that the dilatation can cause incompetence; the incompetence further interferes with the efficiency of the heart and further dilatation follows with consequent further aggravation of the incompetence.

It is probable, also, that as the ring and the chamber of the ventricle dilate, factor (5), i.e. relative shortening of the musculo-tendinous control, is added as an aggravating factor.

\section{The Pathological Changes Observed in Mitral Incompetence}

It is fairly easy to understand and describe the pathological changes in mitral stenosis because of the opportunity that has occurred to study many cases during life and post mortem. Particularly important is the ability to examine the valve mechanism actually working when the finger is inserted into the left atrium at operation.

In mitral regurgitation, however, the position is somewhat different because far fewer cases of incompetence have been operated upon; indeed, until quite recently, we have carefully avoided operating on any patient in whom a high degree of regurgitation is suspected. Moreover, in the past, there has been poor correlation between proper post-mortem study and clinically observed and significant incompetence. In fact many pathologists and physicians just have not understood the distinction between the purely stenosed, the purely incompetent, or the grossly damaged, incompetent and stenosed valve. This is made obvious in most museums, where it can be seen that almost any diseased mitral valve in which the orifice is reduced in size is usually described as an example of mitral stenosis. This in spite of the fact that the orifice is perhaps $3 \mathrm{~cm}$. long and $1.5 \mathrm{~cm}$. wide. Such an orifice, although smaller than nature designed, does not cause a significant obstruction to the flow of blood from the atrium into the ventricle. Such a valve is a disability from the gross regurgitation that occurs through the relatively large orifice. In contrast, as. stated under 
factor (1) above, if the stenosis is so severe as to permit very little blood entering the ventricle, it can scarcely allow a significantly greater amount to regurgitate. One element of the valve damage is the complement of the other. If the stenosis is severe, regurgitation must be small; if regurgitation is severe, stenosis must be small. If we reduce it to extremes we have a state of affairs in which the orifice is completely obstructed, i.e. stenosis is total, regurgitation is nil; conversely if the valve is absent, stenosis is nil, regurgitation is total. Midway between these two extremes we find a certain balance in which the stenosis is of moderate degree, probably not of great significance by itself but becoming clinically and functionally important because it is accompanied by a significant degree of regurgitation through the rigid stoma of moderate size.

The number of cases of proven mitral regurgitation that I have been able to examine at operation and at autopsy is relatively small but it has enabled certain conclusions to be drawn-conclusions that may need modification in the light of further experience. I must emphasize that this study has been based on true incompetence directly observed at operation when the valve has been examined with the finger. This can surely be the only. sound method on which to base a description of mitral incompetence.

Mitral incompetence is observed in the following three forms.

(1) A small regurgitant stream occurring from a small, grossly stenosed, perhaps calcified, orifice (Fig. 16A).

(2) A moderately powerful regurgitant stream occurring from a narrow orifice, but not grossly stenosed; e.g. it may be $1.5-2.5 \mathrm{~cm}$. long and of varying width. Calcification often determines considerable extra reduction in the width (Fig. 16B).

(3) The orifice is large, perhaps $4 \mathrm{~cm} . \times 2 \mathrm{~cm}$., and a powerful current of blood escapes in ventricular systole. To the examining finger the regurgitant stream feels as powerful as if a tap were running. Clearly no stenosis is present as the orifice is at least equal in area to or even greater than that of the aortic outlet (Fig. 16C).

Type 1 can be dismissed at once for reasons already stated. The regurgitation is a relatively minor incident in a high-grade stenosis and it is usually automatically corrected when the cusps are freed by the relief of the stenosis. It is included merely for the sake of completeness and because it has beguiled the thoughts of many away from the really significant problem revealed in the other two forms.

Type 2 is that more commonly seen and represents the most severe grades of damage to the valve by the rheumatic infection. In fact it may be said that the valve as a valve has ceased to exist. The function of a good valve is to let blood pass freely onwards and to prevent its return. If the valve is converted by disease into a rigid diaphragm with a rigid hole so that too little blood can flow through and there is nothing to prevent its flowing back again, the valve may be said to be completely ruined.

The varying proportions that may be assigned to the stenosis and the incompetence from case to case, can be indicated by using the term " mitral valve disease" for some of these examples of

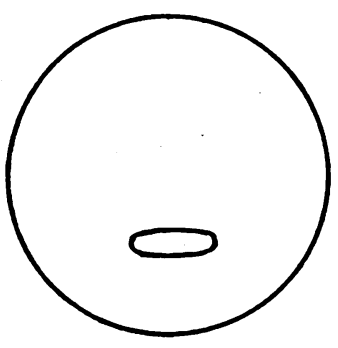

A

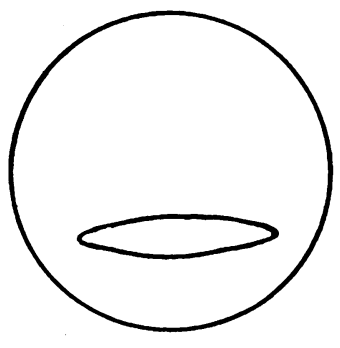

B

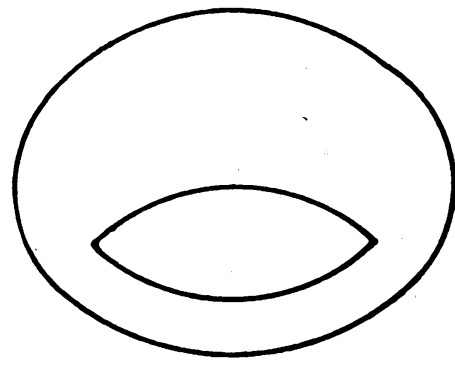

C

Fig. 16.-Diagram of three types of mitral incompetence; see text. 
severe valvular damage exhibited in type 2, rather than using the terms stenosis or regurgitation as descriptive (Bourne, 1952).

The most significant thing the surgeon notices in operating on the cases of mitral valve disease is the importance of the size of the orifice and its correlation with the rigidity or otherwise of the cusps. For instance, in cases of clinically pure mitral stenosis, it is monotonous with what regularity the orifice is found to be some $1 \mathrm{~cm} . \times 0.5 \mathrm{~cm}$. or even smaller: regurgitation is small or absent and depends on rigidity of the edges; the cusps are often thin and supple and the anterior one in particular can be felt to billow freely in systole. In contrasts to scores of this type, one encounters a valve with an orifice that is substantially larger; e.g. $2.5 \mathrm{~cm} . \times 1 \mathrm{~cm}$., with edges that are rigid and fibrous and often grossly calcified. The cusps, too, are rigid and horizontal in both systole and diastole, revealing that movement is slight. A free regurgitant stream is felt during systole and there is often no difficulty in inserting the finger into the orifice and moving it from side to side.

When we examine the valve from such a heart (Fig. 17), we see a state of affairs quite different from that observed in pure mitral stenosis. The most striking feature is total involvement of the valve mechanism from the atrial ring, or even the endocardium of the atrium above, down to the papillary muscles below. The two cusps are thick, rigid, and often severely calcified; the size of the opening has already been mentioned, much larger than in pure mitral stenosis. When, however, we examine the chordæ tendineæ we find that the same primary and maximum adherence has occurred at the critical areas of insertion, but the commissures are very short and often extremely dense and frequently encroached upon by thick fibrous tissue occupying and bridging the peripheral groove between the under surface of the valve cusps and the ventricular muscle. This region may be occupied by exuberant calcium. The distance from the edge of the valve opening to the atrial ring is short (e.g. $0.75 \mathrm{~cm}$. or less), but it must be emphasized that this is not because there has been only a minor peripheral degree of adherence of the cusps. The identification of the fusion in the critical areas contradicts this. The fused, thickened and densely matted chordæ are also seen to be shortened and the dense fibrosis extends down to involve the papillary muscles.

The reason for the larger orifice seems to be severe shortening and contracture of the cusps in all directions so that the central orifice, although diminished in size, is prevented from becoming smaller because of the radiating pull outwards of the fibrous tissue. Instead of the valve cusps
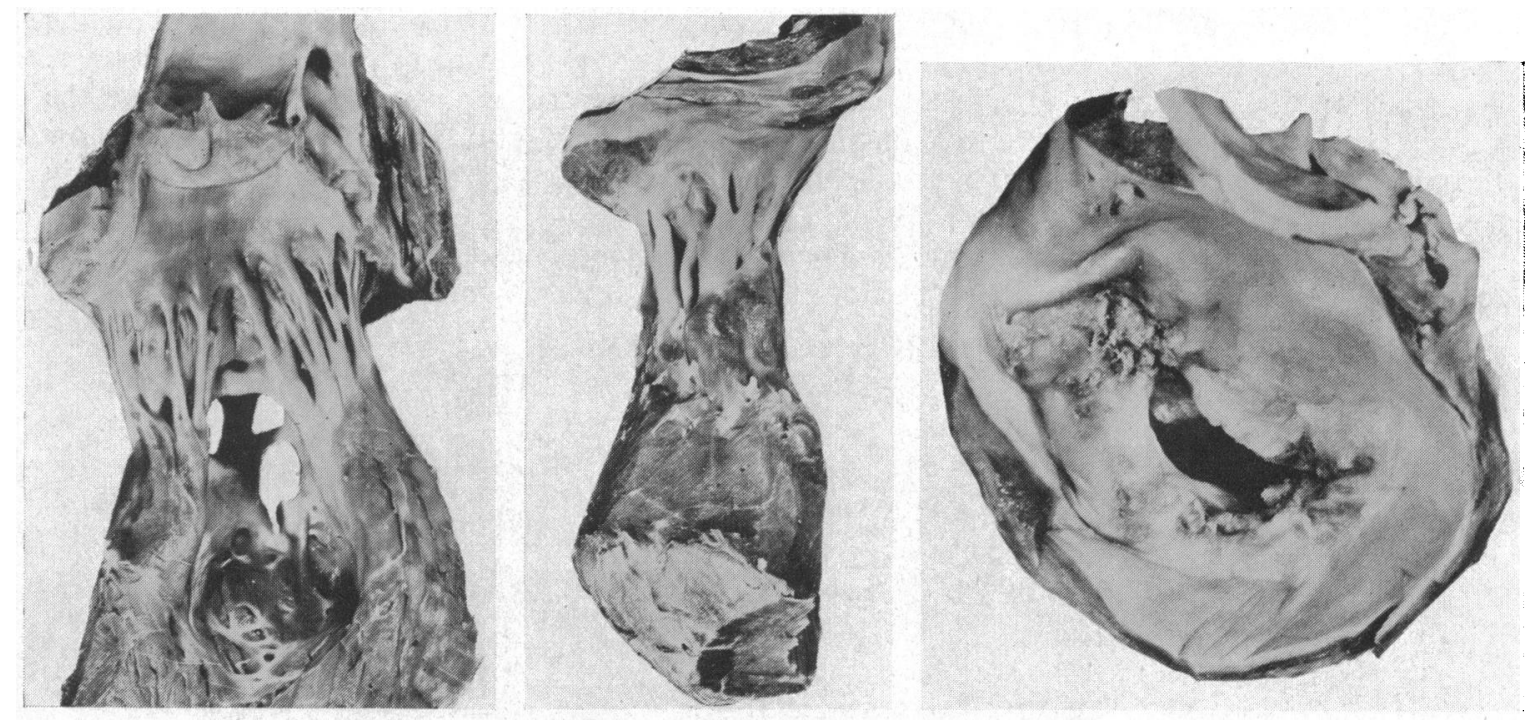

Fig. 17.-A valve from a severe case of mitral incompetence. Note the large, rigid, calcified orifice and the shortened cusps. 
with a small orifice forming a funnel-shaped structure (Fig. 10) as in pure mitral stenosis, the shortened rigid cusps with the larger oval orifice present the typical " button-hole " appearance of the older morbid anatomists. It is necessary to repeat that in this type of valve we see the results of the most severe forms of valvitis.

Occasionally the cusps are not thick, opaque, leathery, and calcified but thin and fibrous, although still rigid and short. The orifice is some $2 \mathrm{~cm}$. long, but the edges are thin and knife-like in their rigidity, instead of being thick and indurated. The commissures are similarly very short and it seems again as if the main process has been a peripheral fibrous contracture with resultant holding open of the central pathway of the fused shortened cusps.

Type 3. I have observed this form on three occasions at operation when clinically very severe mitral incompetence had been assessed: the striking feature is the large size of the orifice which is some $4 \mathrm{~cm} . \times 2 \mathrm{~cm}$., remaining open during systole when a wide and powerful regurgitant stream can be felt. In these cases the margins of the orifice were thin and fibrous, although quite rigid; the cusps thin, but fibrous and short. Both the left ventricle and the left atrium were very large and it was obvious that the atrioventricular ring was much larger in diameter than normal. The impression formed has been that there was not sufficient fibrous thickening to prevent dilatation of the atrial ring, thus the incompetence of the valve was further accentuated and a vicious circle set up.

In Type 2, in which there is a densely productive process, it seems as if the great rigidity of the whole valve mechanism prevents the extreme forms of incompetence developing as a result of progressive dilatation of the ring.

\section{The Surgical Relief of Mitral Stenosis}

It is essential to understand the morbid anatomical changes that can occur in the mitral valve mechanism, if satisfactory operations are to be performed upon the valve. It is not enough to look upon the problem as that of a fibrous diaphragm with a small oval aperture which only has to be made larger. Moreover, it should at once be made clear that although in many cases great improvement in valve function can be achieved by an operation and certainly stenosis can be considerably relieved, in some cases little or nothing can be done to lessen the stenosis or to improve or restore the valve-function by a direct operation on the diseased valve itself. In other words some cases are inoperable unless a means is found of substituting an alternative valve mechanism, possibly combined with partial excision of the damaged cusps.

It is also necessary to stress that the final assessment of the suitability of the valve for operative correction and the prognosis after operation can be made only when the valve is actually examined at operation. Even the presence of heavy calcification radiologically does not prove that the valve cannot be successfully operated upon. Two cases may appear to be identical clinically and yet at operation, one may have a simple stenosis which can be quickly corrected leaving thin supple cusps with a normal opening; the other may have a densely fibrous, rigid opening with short thick fused chordæ tendineæ which totally prevent more than a limited operative correction. In the first the prognosis should be good, in the second it must be uncertain.

Age is no guide. The outlook can still be good in a patient in the late forties or even over fifty, especially if the history is short; a valve with nice supple cusps may be found. In contrast a young patient may have uniformly dense, fibrous contracted valve cusps with thickened, fused, and grossly shortened chordæ tendineæ.

Fig. 18 shows the characteristic arrangement of the stenosed mitral valve viewed from above. The large aortic or anteromedial cusp and the smaller posterolateral cusp are well shown, together with the oblique axis of the valve orifice and the commissures. The fundamental step in valvotomy is, of course, restoration of the normal valve opening and preservation of the cusps by incising or splitting along the line of the fused commissures (Fig. 19).

In dividing the stenosed valve the surgeon must remember its essential funnel-shaped structure 
and its convenient resolution into two parts, a distal transverse or horizontal central portion between the two areas of direct tendon insertion that contains the stenosed orifice, and a more proximal receding or oblique part on each side that extends from the areas of direct tendon insertion to the atrial ring (Fig. 20).

To split the central orifice as far as the two critical areas of tendon insertion on each side is
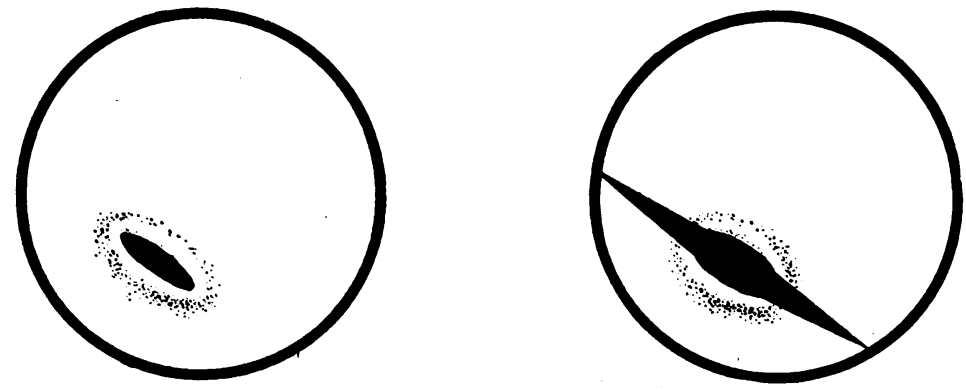

FIG. 19.-Diagram to show the directions in which incisions must be made along the line of the fused commissures if the stenosis is to be relieved in such a way as to restore the normal mechanism of the cusps and to avoid incompetence. 


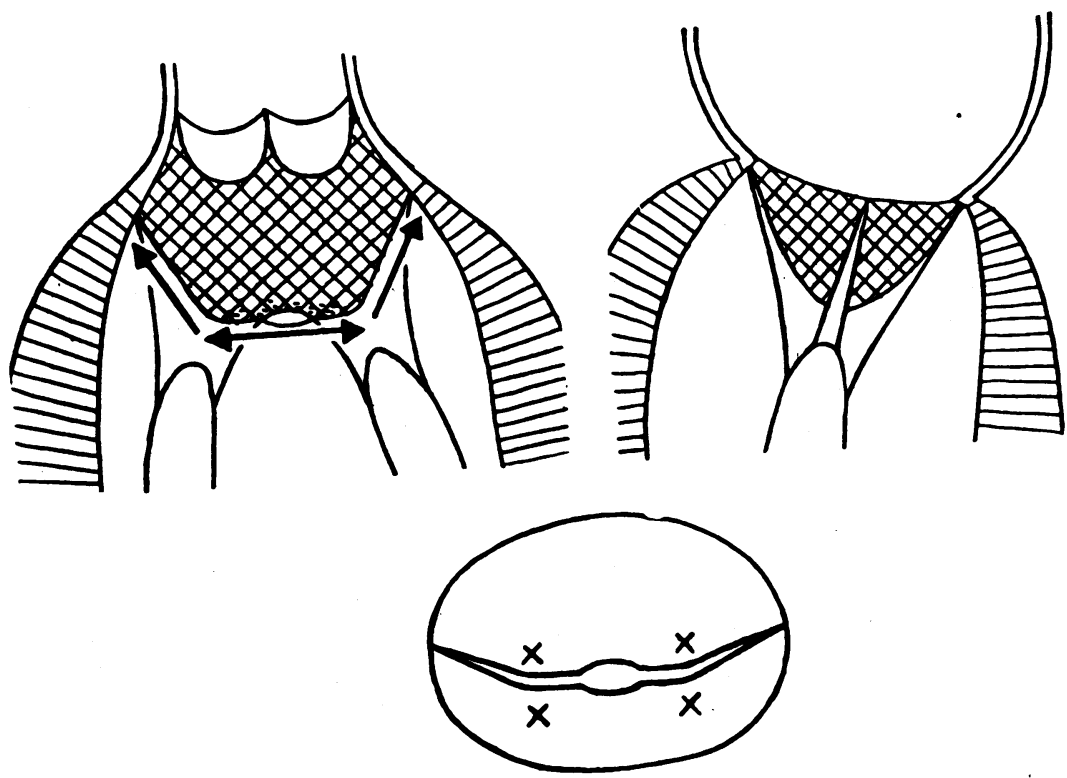

FIG. 20.-Diagram to show the essential mode of division of the stenosed mitral valve; the distal, central, portion is divided horizontally until the fused critical areas of tendon insertion are encountered and freed; the direction of division then becomes obliquely upwards along the sides of the mitral funnel.

usually simple. The resultant opening lies transversely. With the finger tip each main area of tendon insertion is investigated and if it is light and thin the fused valve can readily be split open along the line of the commissures, through the tendon zones, and then in an upward and outward direction (Fig. 20). The receding or ascending parts of the valve may be found almost as thin as tissue-paper.

As soon as the orifice has been enlarged sufficiently to permit the finger-tip to pass through without obstructing the opening completely, an attempt is made to palpate and assess the position and condition of the tendons and the papillary muscles. If the tendons are long, thin and separate, then one can feel confident of achieving an excellent result. Moreover, by identifying the papillary muscle, or muscles if there are two or if they are bifid, the exact line and direction of the commissures can be verified since the tendons spread out from the muscle equally to each cusp.

If firm resistance is encountered by the finger and the cusps do not split easily apart, the finger should be withdrawn and re-inserted bearing an appropriate valvotome. It should be a fundamental requirement of any valvotome that it does not permanently cover the flexor aspect of the terminal phalanx, for by so doing it prevents accurate palpation and localization. The one I favour (after having tried and rejected many designs) is a simple, thin-bladed, supple instrument (Fig. 21A) with which a cut can be made in exactly the right place. The blade slides up and down the finger in a groove in a ring which is worn around the finger base, so that it can be withdrawn to allow palpation and orientation with the finger tip and can then be advanced for the actual cutting (Fig. 21B and C). It can then be slid back again to allow the finger to feel and perhaps continue or complete the division. If the finger cannot complete the task the blade is slid forward once more to be used again.

Once the fibrous zone has been cut the finger may be made to pass between the chordæ tendineæ and the ventricular surface of the cusp; the tendons are often caught up on the under surface and can thus be separated. Thin chordæ tendineæ are sometimes felt actually adherent across the valve orifice so as to form a sort of lattice work in the opening, such an arrangement must be separated with the finger tip and not cut. 


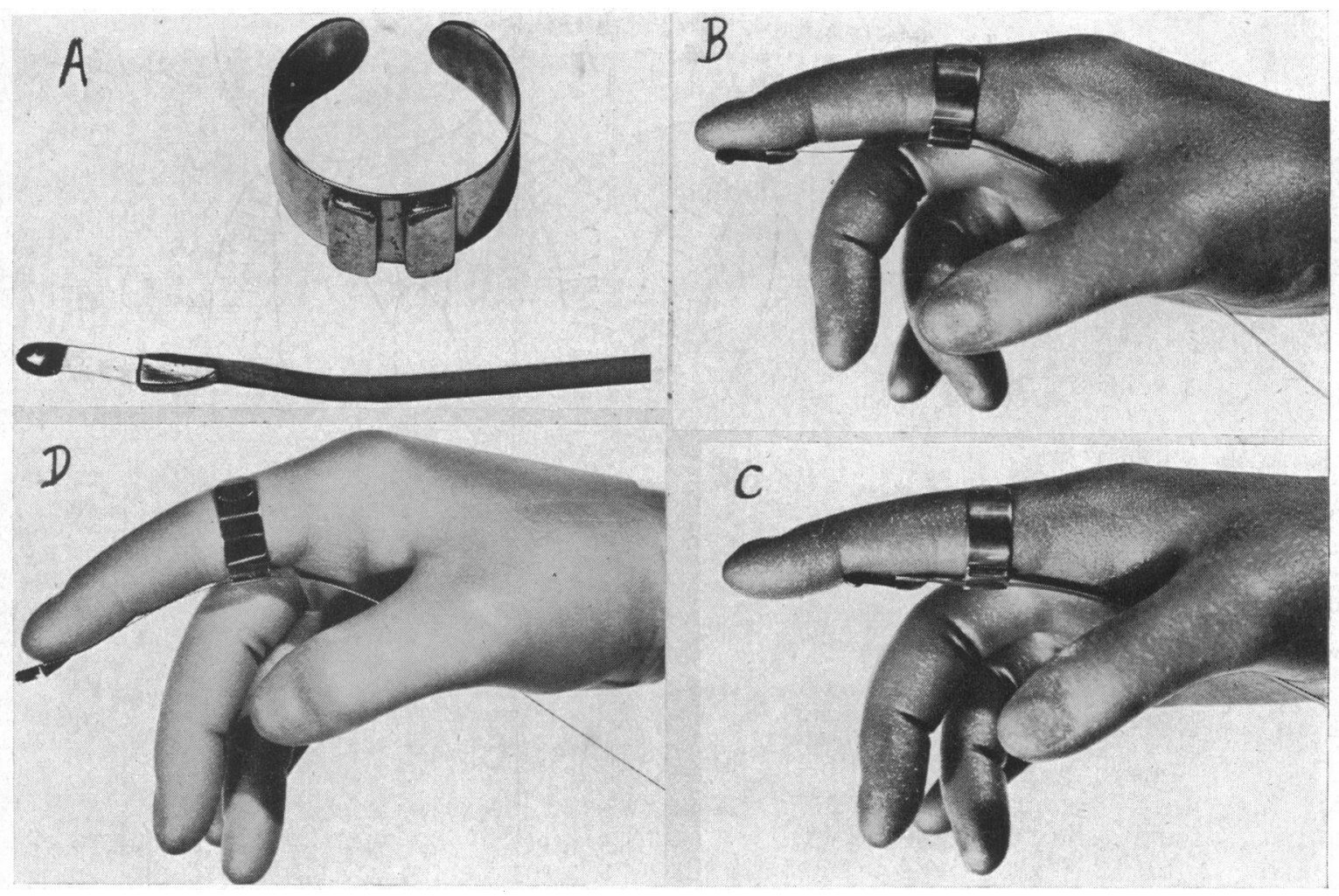

FIG. 21.-(A) Grooved finger ring and blade of valvotome. (B) and (C), To show the use of the valvotome with the blade for the lateral commissures. The instrument is introduced with the blade advanced; it is then retracted to allow the index finger to palpate the exact site for section; the blade is then advanced for the cut. In actual use another glove is worn with most of the index finger cut away. (D) The blade for the medial commissure has a cutting edge distally and along one edge; here again a second glove is worn over the first glove.

The fused valve cusps may be split easily right out to the A-V ring but the cusps may be prevented from opening because the chordæ tendineæ are fused. If light pressure is made downwards the tendons can usually be separated and the tethered cusps now open widely. Exploration of the chordæ tendineæ and papillary muscles is essential; in one case a localized cross fusion between two papillary muscles was recognized and separated.

For splitting the lateral commissure the finger is well flexed. For the medial commissure it is best to keep the finger perfectly straight and push gently but firmly along the line of the commissure with short movements from above downwards. If firm resistance is encountered a valvotome is used in which the cutting part is terminal and along one side (Fig. $21 \mathrm{D}$ ). This simple blade is very efficient for the medial commissure. The division of this commissure with certain instruments is often so awkward and difficult that it is frequently not attempted. Efforts have been made to cut it with the hand fully pronated, a manœuvre that is clumsy and unnecessary even if possible. There is no doubt that the medial commissure is best divided by cutting directly down on it. In this way what used to be a difficult manœuvre becomes quick and easy.

Fig. 20 illustrated the structure of the type of stenosed valve most favourable for division. If the simple, basic structure as detailed here is appreciated the steps of division can be followed easily. The distal transverse division is first made, then the two zones of direct tendon insertion are dealt with and then the ascending limbs of the two commissures are separated as far as the atrioventricular ring on each side. If the filigree pattern of thin separate chordæ tendineæ can be felt passing to their insertion into thin, pliable valve cups, it is fairly certain that the wide and well-functioning valve 
orifice that has been restored (Fig. 22) is unlikely to contract down again unless the patient is unfortunate enough to suffer a further attack of rheumatic valvitis.

Not all valvotomies are as simple as this and the chief difficulty is usually encountered at the critical areas of tendon insertion. When tendons are fused and thickened so as to form large solid fibrous cords on each side of the small valve orifice (Fig. 11 and 12) a difficult situation is faced. In some it may be possible to cut or split the fused mass longitudinally so as to continue the division of the commissures and to allow the cusps to open. When, however, a thick, solid cord is found, as in Fig. 12, it is virtually impossible to carry the division of the valve through the firm barrier. Even if the cusps are split superficial to the fusion, the lateral parts cannot open since they will remain held by the cross fusion of the tendons and secondary fusion is bound to occur (Fig. 23). In these circumstances it may be necessary to be content with enlargement of the small central pathway only as far as the two critical areas. Such an opening can never be more than some $1.5 \mathrm{~cm}$.$2 \mathrm{~cm}$. and is almost bound sobner or later to undergo considerable secondary contracture.

The question is often asked whether recurrence of stenosis is likely after mitral valvotomy. The answer is that, barring further rheumatic valvitis, recurrence is unlikely provided the free movement of the valve cusps is completely restored by ensuring division and separation of the critical areas of tendon insertion. If this is not done, then recurrence is likely. Even if one complete commissure is divided and the corresponding area of direct tendon insertion freed (Fig. 24) a lasting good result should be obtained.

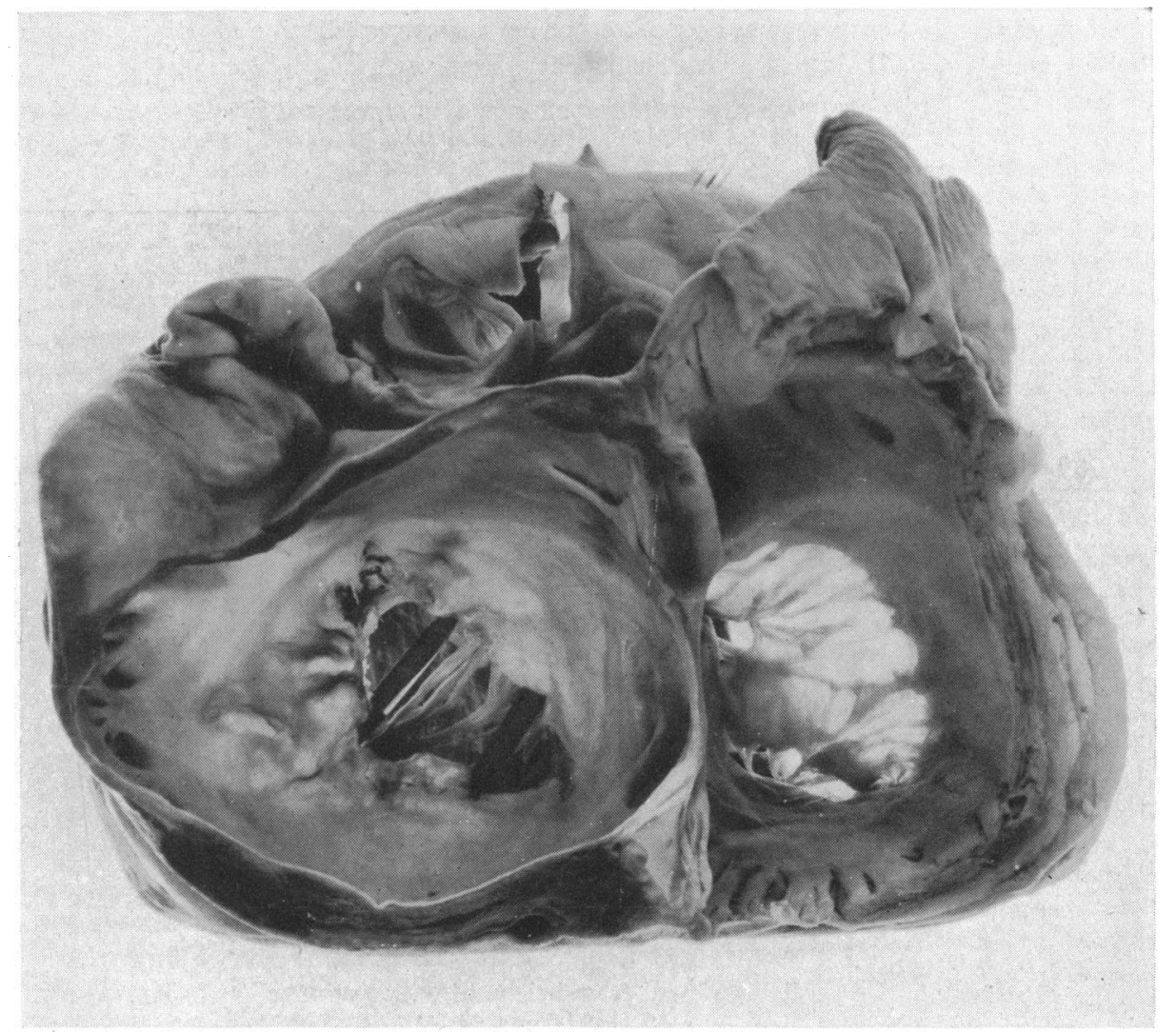

Fig. 22.-Photograph of mitral valve after valvotomy to show the complete restoration of the opening and the reformation of the two functioning flaps. The small size of the original orifice can be seen in the margin of the posterolateral flap. 

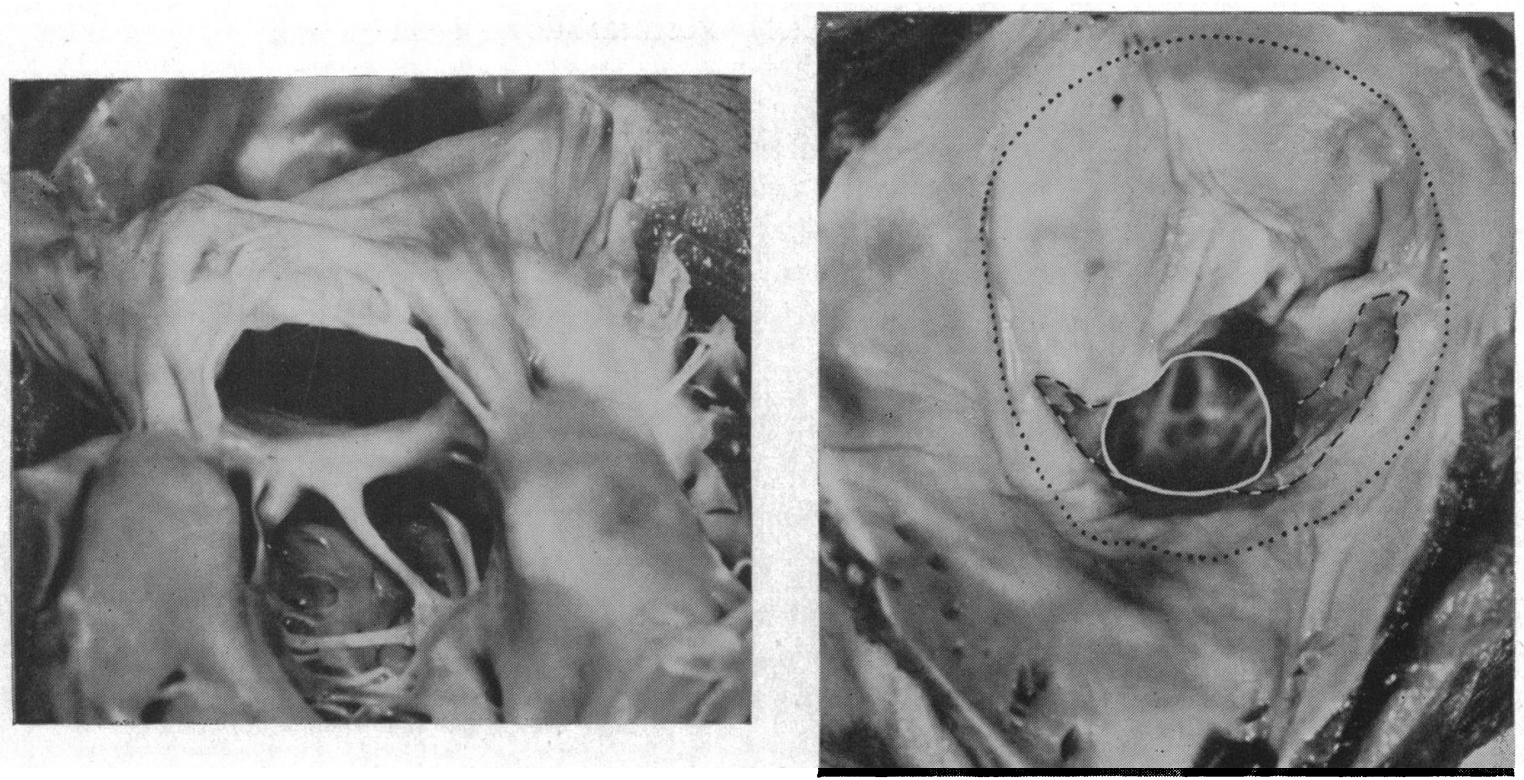

FIG. 23.-Photograph of specimen, two years after valvotomy, to show the mechanism of refusion of the cusps. The commissures of the valve cusps had been completely divided as far out as the atrioventricular ring; the chordæ tendineæ were, however, so solidly fused, that they could not be separated; secondary refusion of the commissures was, therefore, inevitable, although a reasonably good central pathway remained. Sudden death occurred after quinidine therapy. The clinical result had been excellent.

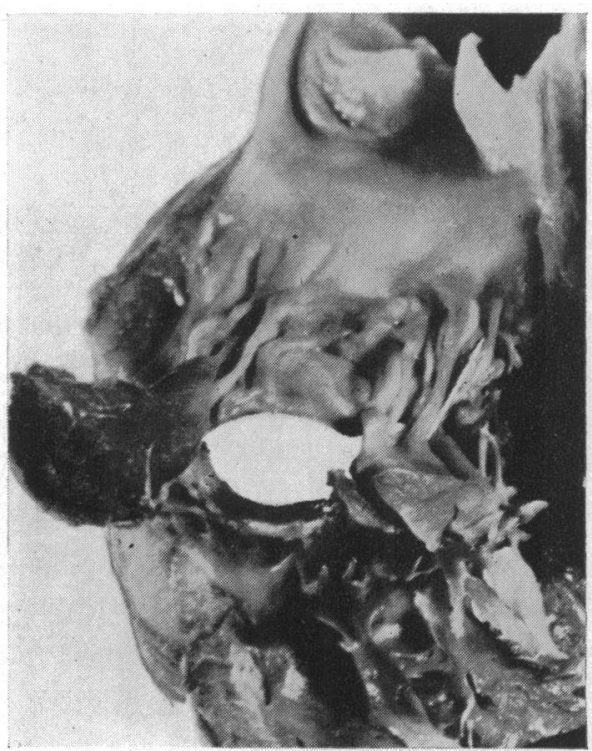

A

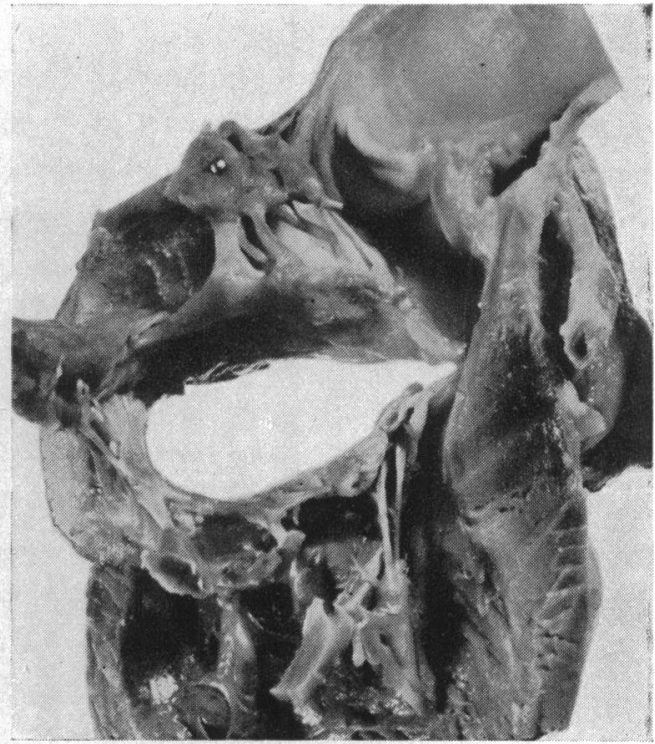

B

FIG. 24.-Photograph of a specimen viewed from below, of mitral stenosis in which, at operation, only one commissure was completely cut. In (A) the chordæ tendineæ of the lateral commissure are placed together as they were before valvotomy; in (B) the chordæ tendineæ of the lateral commissure have been separated to show how the valve cusps are liberated and allowed to open freely. The medial commissure remains fused and this part of the valve cusp, therefore, cannot open. 
If a solid barrier of fused tendons is encountered and the division of the valve is carried round in front of or behind it, incompetence is bound to follow. If the cut passes in front, the aortic cusp will be deprived of its support and the incompetence will be severe and possibly fatal. If the cut passes behind, only the posterolateral cusp will be affected and the regurgitation will be less significant.

\section{The Surgical Relief of Mitral Regurgitation}

The small, rigid, stenosed orifice through which a small amount of regurgitation occurs presents no real problem, for the division of the fused cusps and tendons automatically corrects the regurgitation; which in any case is of an insignificant degree.

The real problem begins when the orifice is not a very small one, but is between $1 \mathrm{~cm}$. and $2 \mathrm{~cm}$. long and from $0.5 \mathrm{~cm}$. to $1 \mathrm{~cm}$. wide, and is rigid, perhaps calcified, and flanked by short, rigid, very fibrous and thickened cusps which form, not a funnel, but an almost flat diaphragm with a button-hole orifice. The chief reason for the valve's incompetence is the shortness of the cusps which prevents overlap or free co-aptation of their edges. The effect of enlarging the orifice by dividing the commissures, an act that in any case is limited by the shortness of the commissures, is in general to make the incompetence worse. The edges of the orifice remain rigid and the cusps are not only too short and stiff to overlap but, from their fibrous nature, may even retract. In only one case have I observed a different action; this was in the case of a woman, aged 54, with a rigid, semi-calcified incompetent orifice. The lateral commissure was almost completely calcified; as the medial commissure was cut the regurgitant stream, which the finger was sensible of, ceased abruptly as if the division of the commissure had allowed the two cusps so to readjust themselves as to become more efficient.

In general it is useless to expect improvement by performing valvotomy on an incompetent rigid valve with short thick cusps and an orifice some $2 \mathrm{~cm}$. long. The decision that must be made is whether some plastic procedure should be used to reinforce or correct the valve's incompetence. There is no doubt that some such procedure is urgently needed because it is a serious thing to operate on a case of mitral valve disease and close the chest again without improving the heart's action; the result is almost certainly the death of the patient. The only reason why thoracotomy and cardiotomy is possible on severely ill patients with mitral stenosis is that the valvotomy immediately improves the heart's action. - If a patient submits to such an operation then he should be given the chance of some real improvement.

In the third type of mitral incompetence, that in which the orifice is very large, the atrial ring very dilated, the cusps short and the degree of regurgitation severe, the problem is even more difficult. The powerful left ventricle and the large valvular defect produce a massive reflux, the control of which is a severe test for any plastic procedure.

Unfortunately at present no reasonably safe and successful procedure is available; the method of introducing pericardial flaps into the ventricle has proved, so far, disappointing and dangerous. Although the present methods have proved disappointing, it is desirable to consider more critically the anatomical problems involved so that an improved method may be evolved with some degree of accuracy.

The insertion of a pericardial flap through two openings, so that it may form a flapper valve to close the incompetent orifice, has certain grave defects in its usual method of application. In order that such a flap should function efficiently it must be disposed at right angles to the long axis of the valve opening (Fig. 25). It could not be parallel to this axis, for the papillary muscles and their tendons are in the way. Fig. 25 shows, diagrammatically but accurately, the disposition of the mitral orifice (cf. Fig. 18, a photograph from an actual specimen). The line A-A indicates the position that must be occupied by a pericardial flap if it is to lie transversely to the long axis of the valve orifice. It will be seen that, anteriorly, it must traverse the outflow track of the left ventricle, the septum, and the outflow track of the right ventricle. Clearly this is impossible. 


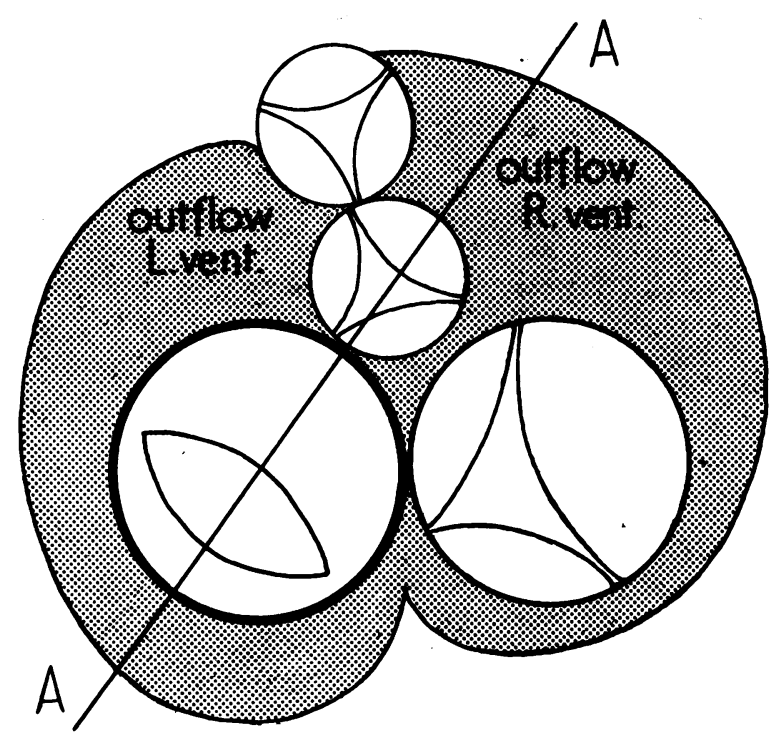

FIG. 25.-Diagram to show the basic anatomy of mitral incompetence. The line A-A indicates that if a pericadial flap with two opposing sites of fixation is to be used in such a way that it is efficient it must lie at right angles to the axis of the valve orifice and inevitably, therefore, it must traverse, in front, the outflow tract of the left ventricle, the septum and the outflow tract of the right ventricle. To avoid these structures it must lie at a much less efficient angle to the optimum line A-A.

If the septum and the right ventricle are to be avoided the anterior fixation must be at an angle considerably less than 90 degrees to the long axis of the valve orifice and in fact forming, not the diameter of the circle of the valve ring, but a chord. Its efficiency in controlling valvular incompetence diminishes as the angle diminishes. Moreover, it is by no means certain that such an ill-disposed flap will be flung against the incompetent mitral orifice in systole. It may just as well, or even more likely, be shot into the outflow channel of the ventricle.

The incompetence is due, fundamentally, to the fact that the two cusps are too short to meet and overlap so as to give mutual support. The most logical method of correction of the disability would seem to be lengthening one or both cusps so that they can reach and overlap. The anterolateral or aortic cusp does not lend itself to such a procedure, seeing that its ventricular surface is directly related to the outflow channel. We must, therefore, turn to the posterolateral cusp which lies essentially in the inflow portion of the ventricle. If this cusp could be either lengthened or reinforced by a flap or some other structure introduced immediately beneath it, its function should be restored (Fig. 26). Thus any material used to correct incompetence should be inserted so that it is hinged posterolaterally, as shown in Fig. 26. This might be a two-pedicled flap of, e.g. pericardium, introduced from outside the ventricle; the disadvantage of this method is that the access

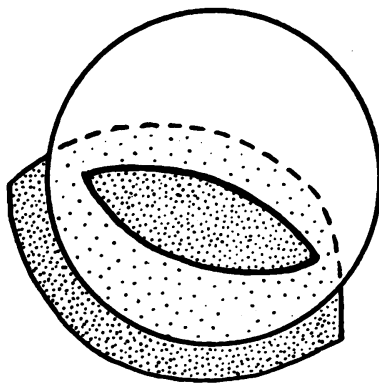

Fig. 26.-Diagram to show suggested correct mode of application of a re-inforcing flap to control mitral regurgitation by extending the surface of contact of the posterolateral cusp. to the relevant part of the ventricle is difficult and awkward. An alternative method is the introduction of a flap from within the heart, sutures being passed through the wall of the ventricle from within outwards to guide the flap into place and to fix it securely. Such a flap can be inserted via the left auricular appendage. This method has the same drawback of difficult access to the correct sites high enough and far enough back on the left ventricle. A flap successfully introduced into position below and re-inforcing the posterolateral cusp must inevitably be flung against or across the valve orifice in systole; it cannot be diverted into the outflow channel.

I have used each of these methods in trial cases, but so far without success. This analysis of the relevant anatomical features, or what would appear to be the relevant features, is put forward, not because it has been proved correct in practice, but because it appears to be sound in theory. It may serve to help in the planning and execution of some alternative form of mitral valvoplasty to correct incompetence. 


\section{REFERENCES}

Bourne, G. (1952). Brit. med. J., 1, 896.

Brock, R. C. (1950). Guy's Hosp. Rep., 99, 236.

Lutembacher, R. (1950). Le Rétrécissement Mitral. Paris.

McMillan, I. K. R., Daley, R., and Matthews, M. B. (1952). Brit. Heart J., 14, 42.

Magarey, F. R. (1951). Brit. med. J., 1, 856.

Quain's Anatomy (1929). 11 th edit., Vol. IV, The Heart. London.

Rusted, I. E., Scheifley, C. H., Edwards, J. E., and Kirklin, J. W. (1951). Proc. Mayo Clin., $26,297$.

Smith, J. C. (1950). Circulation, 1, 766.

Sokoloff, L., Elster, S. K., and Righthand, N. (1950). Circulation, 1, 782. 